\author{
RESEARCH ARTICLE \\ 10.1029/2020JE006470 \\ Key Points: \\ - Sinuous ridges in the Morrison \\ Formation were formed by \\ exhumation of channel belts \\ - Scarp retreat heavily modified \\ channel-belt width but not \\ thickness; a new erosion model \\ relates width and relief to uneroded \\ dimensions \\ - Application to Mars shows \\ consistent paleo-discharge estimates \\ using multiple proxies
}

Supporting Information:

- Supporting Information S1

Correspondence to:

A. T. Hayden,

ahayden@caltech.edu

Citation:

Hayden, A. T., \& Lamb, M. P. (2020). Fluvial sinuous ridges of the Morrison Formation, USA: Meandering, scarp retreat, and implications for Mars. Journal of Geophysical Research: Planets, 125, e2020JE006470. https:// doi.org/10.1029/2020JE006470

Received 27 MAR 2020

Accepted 9 SEP 2020

Accepted article online 12 SEP 2020

\section{Fluvial Sinuous Ridges of the Morrison Formation, USA: Meandering, Scarp Retreat, and Implications for Mars}

\author{
A. T. Hayden ${ }^{1}$ iD and M. P. Lamb ${ }^{1}$ in \\ ${ }^{1}$ Division of Geological and Planetary Sciences, California Institute of Technology, Pasadena, CA, USA
}

\begin{abstract}
Sinuous ridges have been interpreted as evidence for ancient rivers on Mars, but relating ridge geometry to paleo-hydraulics remains uncertain. Three analog ridge systems from the Morrison Formation, Utah, are composed of sandstone caprocks, up to $50 \mathrm{~m}$ wide and $8 \mathrm{~m}$ thick, atop mudstone flanks. Ridge caprocks have narrowed significantly compared to sandstone bodies preserved in outcrop, consistent with a new ridge-erosion model that can be used to estimate original sandstone-body extent. Ridge networks represent caprocks intersecting at distinct stratigraphic levels, rather than a preserved channel network. Caprocks are interpreted as amalgamated channel belts, rather than inverted channels, with dune and bar cross stratification that was used to reconstruct paleo-channel dimensions. Curvilinear features on ridge tops are outcropping lateral accretion sets (LAS) from point bars and indicate meandering. We found that caprock thickness scales with paleo-channel depth and LAS curvature scales with paleo-channel width. Application of these relations to a ridge in Aeolis Dorsa, Mars, yielded consistent water discharge estimates $\left(310-1,800 \mathrm{~m}^{3} / \mathrm{s}\right)$. In contrast, using ridge width or ridge radius of curvature as paleo-channel proxies overestimated discharge by a factor of 30-500. In addition, the ridge-erosion model suggests that scarp retreat may be less efficient on Mars, resulting in taller and wider ridges, with more intact caprocks. Altogether, our results support the hypothesis that ridges are exhumed channel belts and floodplain deposits implying long-lived fluvial activity recorded within a depositional basin.
\end{abstract}

Plain Language Summary Ridges across Mars have sinuous shapes that resemble rivers, but they are topographic highs (hills) rather than troughs. These landforms potentially hold valuable clues about ancient rivers that once flowed on Mars, but to decipher these clues, we must understand how the ridges formed. We studied ridges in Utah that resemble the Martian ridges and may have formed in a similar way. We found that the Utah ridges are composed of sandstone caprocks that overlie mudstone and are from a thick sequence of sedimentary rocks from the Jurassic period. The sandstones were deposited by rivers as a channel belt, and the mudstones represent the neighboring river floodplains. These rocks were subsequently uplifted, and ridges formed as the weaker mudstones eroded faster than the sandstones. We found that both the thickness of the sandstones and curvature of bar-accretion surfaces within can be used to approximate ancient river water discharge. We also found that the sandstones have been narrowed by erosion, and we developed a scarp-erosion model describing this process. We applied the methods tested in Utah to ridges on Mars and found consistent agreement. Our results suggest that the ridges on Mars are exhumed and eroded deposits from ancient river-channel belts.

\section{Introduction}

The surface of Mars has topographic ridges in places (e.g., Figure 1) that have a planform shape similar to rivers and have been used to constrain hydrology through time (e.g., Burr et al., 2009, 2010; Jacobsen \& Burr, 2018; Kite et al., 2013, 2019; Palucis et al., 2014). Ridges can form in a variety of ways, but ridges with an inferred fluvial origin (fluvial ridges) have been used to characterize the history of water on Mars because they are common (e.g., Burr et al., 2009; Davis et al., 2016, 2019), planet spanning, and visible from orbit (Figure 1). Because of their association with liquid water, fluvial ridges are important for exploration, including at landing sites for rovers like Mars 2020 (Jezero Crater; Goudge et al., 2018) and ExoMars (Balme et al., 2020). Ridges on Mars also have been used to argue for unexpectedly wide rivers (Kite et al., 2019), large seas or oceans (Cardenas et al., 2018; DiBiase et al., 2013; Hughes et al., 2019), significant durations of fluvial activity (Kite et al., 2013), and other indicators of a likely warm and wet early climate (e.g., Davis et al., 2016).
(C)2020. American Geophysical Union. All Rights Reserved. 


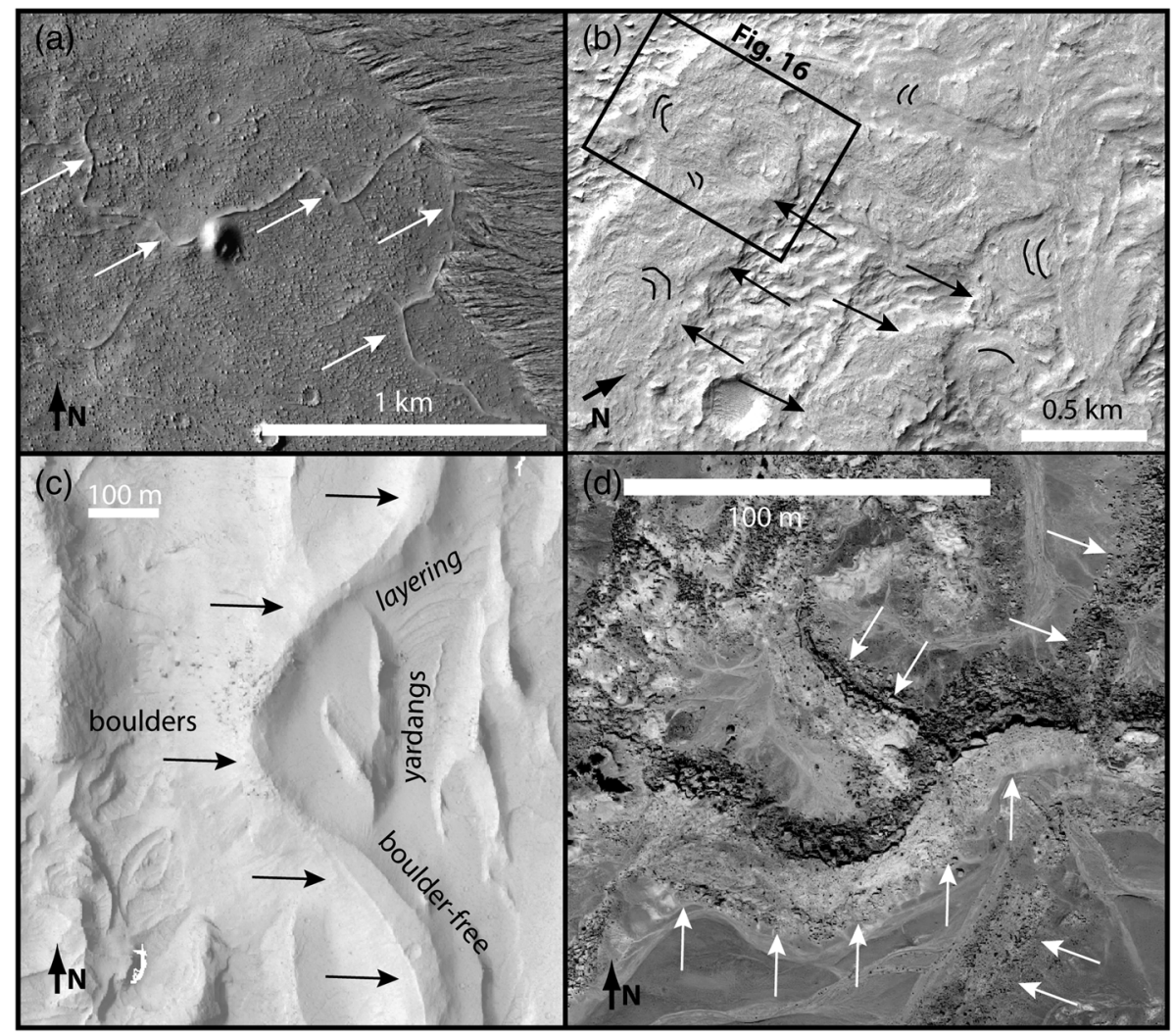

Figure 1. Examples of fluvial ridges from Mars and Earth. Arrows point to ridges; each arrow orientation follows a single ridge. (a) Long ridges being exhumed from cliffs (3.23 S, $152.29 \mathrm{E}$; Aeolis Dorsa, Mars; CTX image P22_009478_1768_XN_03S207W; credit: NASA/JPL/Malin Space Science Systems). (b) Sinuous ridge on Mars, showing lateral accretion sets (indicated by black arcs) (5.96 S, 153.43 E; Aeolis Dorsa; HiRISE image ESP_02085_1740).

(c) Variable boulder cover and caprock widths on a ridge in Aeolis Dorsa (6.111 S, 151.430 E; HiRISE PSP_002279_1735). (d) Stacked sinuous ridges being exhumed from a cliff in our Ferron Creek North site in Utah (39.136, -110.925; image from National Agriculture Image Program).

Fluvial ridges form when a body of rock that has a plan view shape similar to a river is exhumed by differential erosion of the surrounding material (Pain et al., 2007; Pain \& Oilier, 1995). Two main hypotheses exist for forming that body of rock. If the indurated material, whether of fluvial or nonfluvial origin, fills a river channel and forms a cast then the subsequent ridge can preserve the paleo-channel and channel-network geometry at a snapshot in time (e.g., Stanislaus Table Mountain, CA; Burr et al., 2009). This process is termed topographic inversion because what was in negative relief now stands in positive relief, and the resulting ridges are called inverted channels (Figure 2a). Here we use the term channel to reflect the topographic trough that is a conduit for river water flow, whereas the channel-filling material-lava, in the case of Stanislaus Table Mountain-is a channel fill because it preserves the shape of the channel. Channel fills are not common in fluvial deposits, but they can occur, for example, when a meander bend cuts off and the resulting abandoned channel loop (or oxbow lake) fills with overbank mud without significant modification to the channel geometry (e.g., Blum et al., 2013; Bridge, 2003; Gibling, 2006). Fluvial channel fills are important where preserved because they record the original channel shape and can be used to estimate paleo-discharge (Bhattacharya et al., 2016; Musial et al., 2012; Reijenstein et al., 2011). Hence, the inverted channel interpretation implies topographic inversion of a channel fill (e.g., Burr et al., 2010). However, muddy channel fills are often easily eroded and, thus, have not been observed to form ridges on Earth during exhumation; lava channel fills, on the other hand, can produce ridges.

The alternate hypothesis suggests that the indurated ridge-forming material is a channel-belt deposit, and when exhumed, the process is referred to as deposit inversion rather than topographic inversion (DiBiase et al., 2013; Hayden et al., 2019; Figure 2b). River channels build deposits of coarse-grained (sandy) 


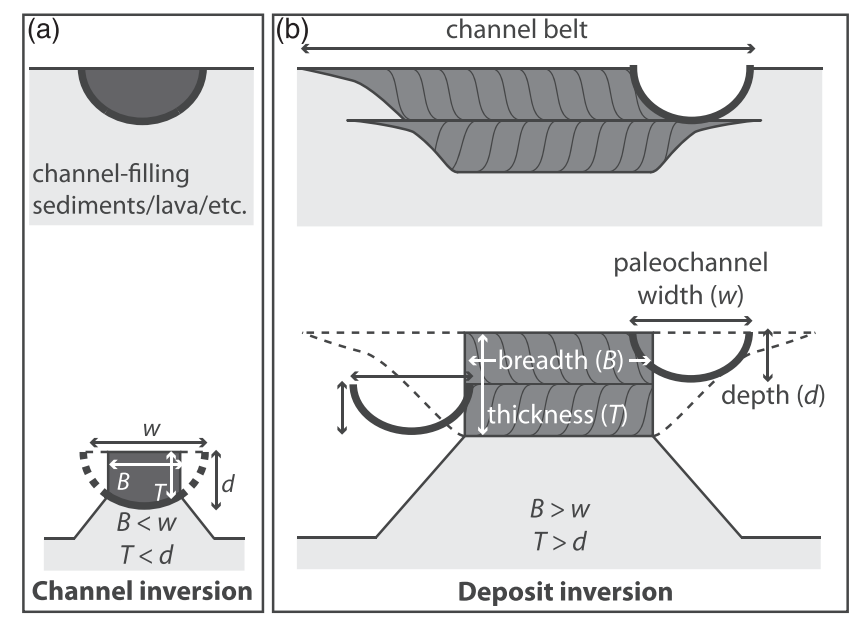

Figure 2. Schematic hypotheses for the formation of fluvial sinuous ridges and deposit stratigraphy, after Hayden et al. (2019). (a) Schematic of the topographic inversion hypothesis: A channel (black semicircle) has been filled with a resistant material (dark gray) and is subsequently exhumed to form a ridge with caprock dimensions (breadth, B, and thickness, $T$ ) that are slightly smaller than the original channel dimensions (width, $w$, and depth, $d$ ) due to erosion. (b) Schematic of the deposit inversion hypothesis: A channel (black semicircle) aggrades and migrates across the floodplain (light gray), building a channel-belt sandstone body (medium gray) that is larger than the original channel. During exhumation, erosion modifies the channel-belt sandstone primarily by lateral backwasting reducing the ridge width. sediment that are far more extensive laterally and vertically than the river channel as a result of channel lateral migration and aggradation within an otherwise muddy floodplain (e.g., Gibling, 2006; Jerolmack \& Mohrig, 2007; Mohrig et al., 2000). Channel deposits are accreted at the margins of an active channel as it shifts laterally and aggrades vertically and, thus, are distinctly different than fluvial channel fills. We refer to the body of amalgamated channel deposits as a channel belt (also known as a channel-belt sand body, channel sandstone body, channel body, or channel complex; Blum et al., 2013; DiBiase et al., 2013; Gibling, 2006). Channel belts by our definition can contain stratigraphic packages that record single or multiple generations of channel lateral migration and vertical accretion (i.e., multiple stories) (Mackey \& Bridge, 1995). Stacked sandstone channel belts within a muddy floodplain facies represent the dominant stratigraphic architecture of fluvial deposits (Hajek \& Wolinsky, 2012; Heller et al., 2015).

Discerning between a topographically inverted channel and an exhumed channel belt is important for a number of reasons. First, the different formation mechanisms imply different durations of fluvial activity recorded in the ridge: Inverted channels imply a relict geomorphic surface that was preserved at an instant in time, whereas exhumed channel belts imply partial deflation of a depositional basin that may have been constructed over thousands to millions of years. Second, the interpretation defines the relationship between the geometry of the ridges and the paleo-channels, which is needed to constrain ancient surface hydrology of Mars. As an example, Lefort et al. (2012) interpreted a branching network of ridges as a topographically inverted tributary network based on observations of increasing elevation with increasing distance from the branch point. However, DiBiase et al. (2013) and Lefort et al. (2015) interpreted the same landform to have paleo-flow in the opposite direction based on the observations that branching was likely from distributary channel belts and that modern topographic slope was likely modified by subsequent erosion or crustal deformation. The interpretations also change the quantification of river discharge from ridge observations. For example, Hayden et al. (2019) demonstrated over 2 orders of magnitude of uncertainty in relating ridge width to paleo-channel width due to lateral accretion and amalgamation of channel deposits during channel-belt formation and scarp retreat during ridge exhumation. This uncertainty is amplified in calculations relying on channel width; for example, discharge is commonly calculated using a relation that depends approximately on channel width squared (e.g., Eaton, 2013; Williams, 1986, 1988).

In addition to ridge width, another property of ridges used to reconstruct paleo-channels is ridge curvature and wavelength because curvature in meandering rivers scales with river width and discharge (e.g., Dury, 1976; Williams, 1986, 1988). Under the inverted channel hypothesis, ridge centerline curvature has been used as a proxy for channel curvature. It has been argued that ridge curvature is less affected by erosion than ridge width (Burr et al., 2010; Kite et al., 2015). However, it is uncertain whether this method applies when the ridges are actually exhumed channel belts because it is unlikely that channel-belt curvature mirrors paleo-channel curvature. Curvature-based reconstructions have also been applied to subparallel, concentric, curvilinear features on the surface of ridges on Mars that are observed in orbital images (e.g., Cardenas et al., 2018; Goudge et al., 2018; Malin \& Edgett, 2003; Figure 1b). In cases, the curves co-occur with an undulating topography that is reminiscent of scroll bars, or abandoned river levees, associated with meandering rivers on Earth. If they are preserved levees, they could be useful because levees bound channels (Ferguson \& Brierley, 1999; Leopold et al., 1964). However, levees are unlikely to be preserved both during amalgamation of channel deposits (Mason \& Mohrig, 2019) and during exhumation and erosion to form a ridge. Instead, the curvilinear features may be erosional landforms; that is, exposed traces of channel-margin lateral accretion sets (LAS) as they intersect the deflating land surface. Both scroll bars and LAS are indicative of a laterally migrating river channel (Figure 3); however, their curvature has been observed to differ by up to a factor of 20, with scroll bar curvature being less representative of channel geometry (Mason \& 


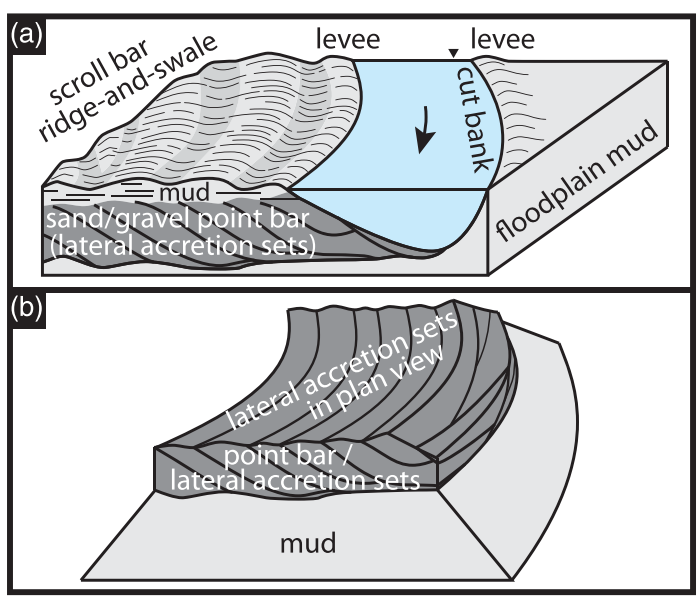

Figure 3. Comparison of modern scroll bars (a) and exhumed point bars (b). (a) A channel migrating laterally generates ridge-and-swale topography at its surface from secondary flow circulating muddy overbank deposits. In the subsurface, the migrating channel creates lateral accretion sets that are typically coarse grained (sand and/or gravel), sometimes separated by muddy deposits. Panel modified after Shiers et al. (2019). (b) Exhumed point bar (i.e., panel a after the mudstone, including scroll bar, has been eroded away). Fine-grained deposits often erode more quickly than coarse-grained deposits, which results in the sand body standing in positive relief while the mud of the scroll bar and fluvial channel fill are eroded. At the finer scale, the muddy laminations between lateral accretion sets also erode, causing a topography reminiscent of the ridges and swales of a scroll bar, though it arises from a different set of processes.
Mohrig, 2019). There has yet to be an analysis of similar curvilinear features of ridges on Earth to help constrain their origin.

Another uncertainty in interpreting fluvial ridges is the extent to which they are eroded. Erosional modification of ridge geometry has long been noted (Derr, 1974). Ridges on Mars have abundant yardangs and gaps between ridge segments (Burr et al., 2009, 2010). Williams et al. (2009) and Hayden et al. (2019) observed that variability in breadth of ridges in the Cedar Mountain Formation is likely due to erosion. Williams et al. (2009) proposed that using the upper third quartile of ridge breadth might compensate for erosion. Hayden et al. (2019) found that ridge caprock breadths were between 0.2 and 2 times the width of the paleochannels as reconstructed from sedimentological observations. However, neither study documented the outcrops of uneroded sandstone bodies that are needed to directly constrain the amount or mechanism of narrowing during ridge formation.

To address uncertainties in formation of fluvial sinuous ridges and paleohydraulic reconstructions, here we report new observations of fluvial sinuous ridges from the Jurassic Morrison Formation in eastern Utah. We selected sites that showed visible examples of ridges protruding from cliff outcrops, enabling quantification of ridge erosion, and ridges with LAS traces visible from orbital images, enabling an assessment of LAS and ridge curvature as proxies for channel curvature. Terrestrial analogs have been important to the study of fluvial ridges because detailed in situ analyses cannot readily be performed for ridges on Mars. In particular, detailed sedimentological analysis of ridge deposits on Earth has allowed for the assessment of channel inversion versus deposit inversion and provided a baseline to test paleo-hydraulic reconstruction methods (Hayden et al., 2019; Williams et al., 2009). After describing the study sites in section 2, we discuss our field methods in section 3 and paleo-hydraulic reconstruction methods in section 4. Section 5 presents the field observations, which we use in section 6 to develop and test a scarp-retreat erosion model for ridge narrowing that can be used to reconstruct original channel-belt widths. We also compare the paleo-hydraulic reconstruction methods in section 6 and apply those methods to an example ridge in the Aeolis Dorsa region of Mars.

\section{Study Site and Background}

We studied terrestrial-analog fluvial ridges in the Morrison Formation, southwest Utah. We focused our work on three main sites: the Ferron Creek North (FCN) site in the Brushy Basin Member of the Morrison Formation and Ferron Creek South (FCS) and Wild Horse Mesa (WHM) sites in the Salt Wash Member of the Morrison Formation (Figure 4). Sites were selected from outcrops of the Morrison Formation around the San Rafael Swell for the prominent ridges with neighboring cliff outcrop exposures (FCN and WHM) or LAS (FCS), as observed in aerial images. Most previous work on ridge formation in the area took place nearer to the Green River site in the Cedar Mountain Formation (Cardenas et al., 2020; Hayden et al., 2019; Williams et al., 2007, 2009, 2011). The Cedar Mountain Formation sits directly above the Morrison Formation (Kirkland et al., 1999).

Ridges in the Morrison Formation were first studied by Derr (1974), who used the three-dimensional exposures to study the fluvial structures, interpreting dune trough cross strata and point bar strata as deposits from meandering rivers. Derr neglected amalgamation and erosion and assumed that the ridge sandstone caprocks directly represent the paleo-channel geometry (i.e., width and depth) and used empirical relations from Schumm (1972) to estimate paleo-discharge of 100-1,000 $\mathrm{m}^{3} / \mathrm{s}$. Williams et al. (2007) and Clarke and Stoker (2011) identified ridges in different parts of the Brushy Basin Member as analogs for ridges on Mars. Williams et al. (2007) observed that ridges in the Morrison Formation comprised point bar, channel, and overbank deposits and noted similarities to fluvial strata and stacked ridges observed on Mars. Clarke 


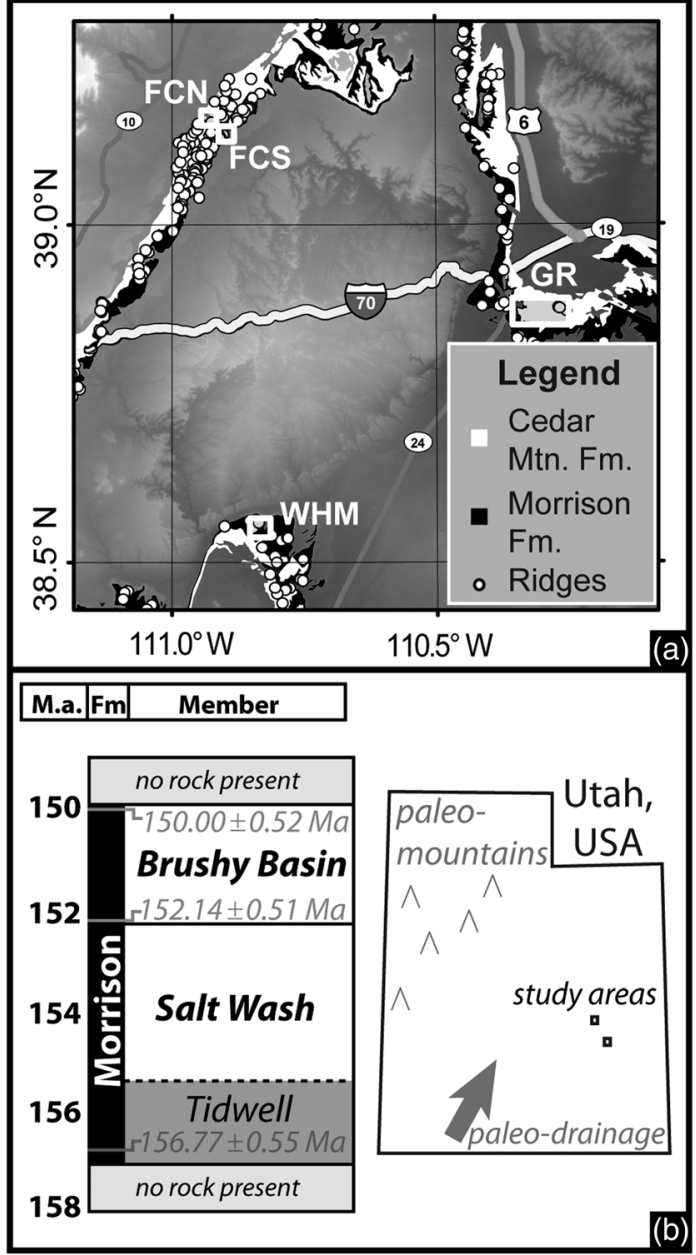

Figure 4. Field area. (a) San Rafael Swell, Utah, USA, topography shown in grayscale. The Morrison and Cedar Mountain Formations outcrop around the San Rafael Swell. There are many sinuous ridges throughout the formations; we focus on three sites in this paper (FCN, FCS, and WHM). The remaining site (GR) is the Green River site studied by Williams et al. (2007, 2009, 2011), Hayden et al. (2019), and Cardenas et al. (2020). (b) Representative stratigraphic section of upper Morrison Formation (dates from Trujillo \& Kowallis, 2015) and interpreted paleogeography of the study areas. and Stoker (2011) interpreted an anastomosing river morphology based on ridges to the east of our WHM site.

The Morrison Formation contains fluvial sedimentary rocks spread across the interior United States, covering Montana, Wyoming, Utah, Colorado, New Mexico, and Arizona, broadly reflecting sediment deposition from the Cordilleran deformation belt (Christiansen et al., 2015; Stokes, 1944, 1961; Figure 4). It contains vertically and laterally amalgamated (i.e., multistory) fluvial sandstones with nonmarine mudstones and siltstones (Tyler \& Ethridge, 1983). Fluvial morphology in some cases has been interpreted as braided based on width-thickness ratios of sandstone bodies, grain size, interpreted sinuosity, interpreted paleoenvironment, and an apparent lack of LAS (Chesley \& Leier, 2018; Kjemperud et al., 2008; Peterson, 1984; Robinson \& McCabe, 1997). However, other workers identified LAS and interpreted a meandering planform (Derr, 1974; Hartley et al., 2015; Heller et al., 2015).

The Brushy Basin Member is the topmost member of the Morrison Formation in our field area. A nearby stratigraphic section at Little Cedar Mountain indicates $100 \mathrm{~m}$ total thickness. Deposition occurred between 152.14 and $150.00 \mathrm{Ma}$ based on recalibrated ash dates (Trujillo \& Kowallis, 2015). Ashes taken from the Brushy Basin Member at other locations have dates ranging from 149.7 to $151.23 \mathrm{Ma}$ (Trujillo \& Kowallis, 2015). This member contains paleosols indicating a semiarid to wet climate (Demko et al., 2004) and ichnofossils indicating that the climate was wetter up section (Hasiotis, 2004). Fluvial morphology of the Brushy Basin has a variety of interpretations (Demko et al., 2004; Galli, 2014; Yingling \& Heller, 1992), but most recently, Heller et al. (2015) interpreted high channel sinuosities and a meandering river pattern.

The Salt Wash Member underlies the Brushy Basin Member and was formed during a subset of the time between 157 and $152 \mathrm{Ma}$ (Trujillo \& Kowallis, 2015). It represents a fluvial megafan that prograded from the syntaxis of the Mogollon Highlands and the Sevier mountain front (Owen et al., 2015; Turner \& Peterson, 2004; Tyler \& Ethridge, 1983). The channel belts are more densely stacked in the Salt Wash Member than in the Brushy Basin Member, forming larger and more amalgamated sandstone bodies (Heller et al., 2015). Robinson and McCabe (1997) found ratios of sandstone body width, $B_{0}$, to thickness, $T_{0}$, ranging from 10 to 70 . Owen et al. (2015) quantified proximal to distal trends and found total thickness of the Salt Wash Member decreases from 174 to $40 \mathrm{~m}$, and average channel belt thickness decreases from 15 to $3.8 \mathrm{~m}$. As with the Brushy Basin Member, the Salt Wash Member was interpreted as a braided system (Kjemperud et al., 2008; Peterson, 1984; Robinson \& McCabe, 1997) but, more recently, has been argued to be a meandering system due to the presence of LAS observed from orbital images (Hartley et al., 2015). Chesley and Leier (2018) interpreted small sandstone bodies as crevasse-splay deposits, medium sandstone bodies with LAS as deposits from laterally migrating sand-bedded-river deposits, and large sandstone bodies as amalgamated braided-river deposits on the basis of having amalgamated downstream-accreting bar strata. They also noted that vertically juxtaposed sandstone bodies can have paleo-flow indicators that differ by more than $90^{\circ}$.

\section{Field Methods}

We used air photos and digital elevation models (DEMs) to study ridge morphology. Aerial photographs came from the National Agricultural Image Program 2016 data set at $1 \mathrm{~m} / \mathrm{px}$ and from our own quadcopter surveys. We used quadcopter images to generate orthorectified images with AgiSoft Metashape at $10 \mathrm{~cm} / \mathrm{px}$. 


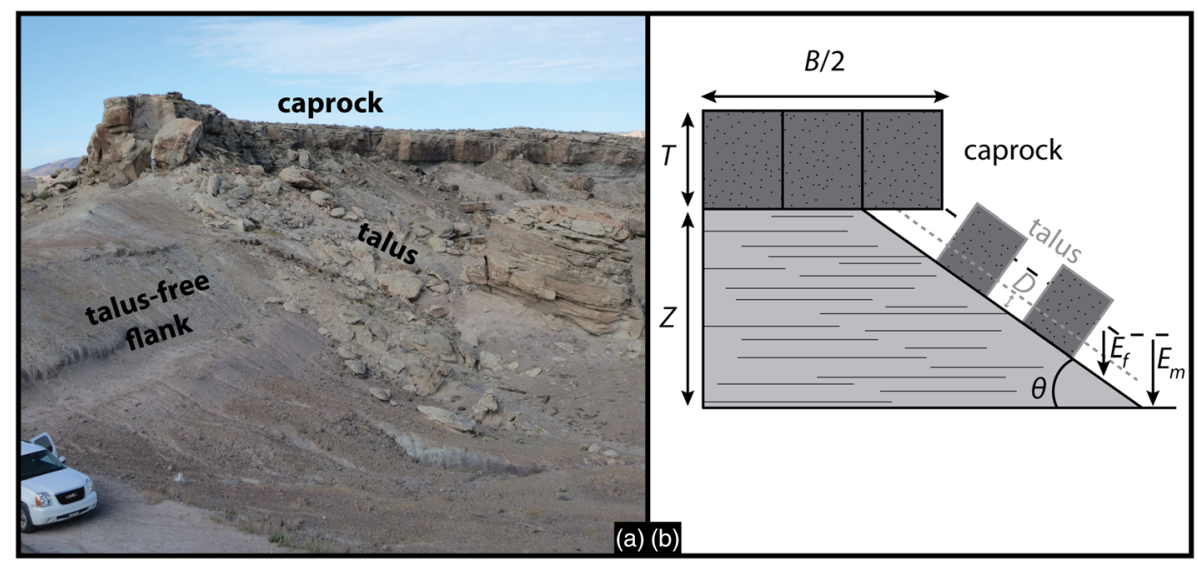

Figure 5. Description of ridge geometry and measurements. (a) Photo of a ridge in the GR field area. The talus-armored section of the ridge retains caprock while the talus-free section has no caprock. (b) Sketch of an idealized ridge of height $(Z)$, caprock thickness $(T)$, breadth $(B)$, and flank slope $(\theta)$. In our erosion model (section 6.2), the surrounding plains erode vertically at the rate $E_{m}$, the flank erodes vertically at the rate $E_{f}$, and there is an average talus thickness, $D$, on the flank slope.

DEMs at $50 \mathrm{~cm} / \mathrm{px}$ were acquired by airborne lidar for the Ferron Creek sites. For the WHM site, we used a $5 \mathrm{~m} / \mathrm{px}$ DEM from the Utah Automated Geographic Reference Center. Ridge measurements were made after removing the local tectonic dip $\left(\sim 4^{\circ}\right.$ to the WNW for the Ferron Creek sites and $5^{\circ}$ to the SW for the WHM site; Doelling et al., 2015; Witkind, 2004). Ridge centerline elevations, caprock extent, and the edge of talus slope were manually traced in the high-resolution air photos. Axes-perpendicular transects were generated along the ridge centerlines at $50 \mathrm{~m}$ spacing. These transects were used to generate elevation profiles from the DEMs. For each profile, we manually defined the top and bottom of the caprock as the most vertical portion at the top of the ridge and defined the base of the talus slope from the plan view photo. Ridge relief $(Z)$ for each transect was calculated as the elevation between the base of the talus slope and the base of the caprock, caprock thickness $(T)$ was measured as the elevation between the top and bottom of the caprock, and ridge flank slope $(\theta)$ was measured as the angle above horizontal for the line connecting the bottom of the caprock and talus slope (Figure 5). Ridge breadth (B) was measured as the distance along the transect between the caprock boundaries defined from the air photos. Breadth was measured once for each transect, while relief, thickness, and slope were measured once on each side. Ridge centerline radius of curvature $(C)$ was taken by visually fitting a circle to the ridge centerline at each bend following the methods of Williams (1986).

We made sedimentological observations in the field in vertical sections up the ridges, measuring the thickness of every bed $>2 \mathrm{~cm}$ using a ruler, median grainsize $\left(D_{50}\right)$ using a sand card, and noting sedimentary structures (Figure 6). For each caprock, we calculated the mean grainsize, weighting measurements by the bed thickness. We measured the thickness of sets of cross stratification using a ruler and recorded their accretion direction. Channel deposits in sand-bedded rivers are often organized into channel bars, dunes, and ripples, which all make distinct scales of inclined stratification. Ripple cross strata are the smallest scale $(<2 \mathrm{~cm}$ in the field area; Figure $6 \mathrm{a})$. Dune trough cross strata are often larger $(<1 \mathrm{~m}$ in our field area) and form trough shapes that are viewed in outcrop as festoon or curving sets (Figure $6 \mathrm{~b}$ ) or in plan view as rib and furrow structures visible on ridge tops (Figure 6c). We used ripple and dune accretion directions as paleo-current direction indicators (e.g., McLaurin \& Steel, 2007; Smith, 1972). We interpreted the largest mode of cross strata as bar clinoforms (Figure 6d). Complete bar strata typically have a sigmoidal shape, but bar strata in our field area are all truncated. Bars can migrate in downstream or cross-stream directions and bar-scale cross sets indicating cross-stream accretion, for example, due to point bar growth in a meandering river (Hartley et al., 2015), were interpreted as LAS (e.g., Figure 3). We measured the radius of curvature of the LAS in plan view $\left(C_{L A S}\right)$ by visually fitting circles to the LAS traces observed in aerial images of ridge tops, taking multiple measurements for each bend segment where multiple LAS were visible.

We also mapped channel belts exposed in cliff outcrops that were connected to ridges. For these cases, we measured the width and thickness of the channel-belt sandstone body exposed in the cliff exposure using 


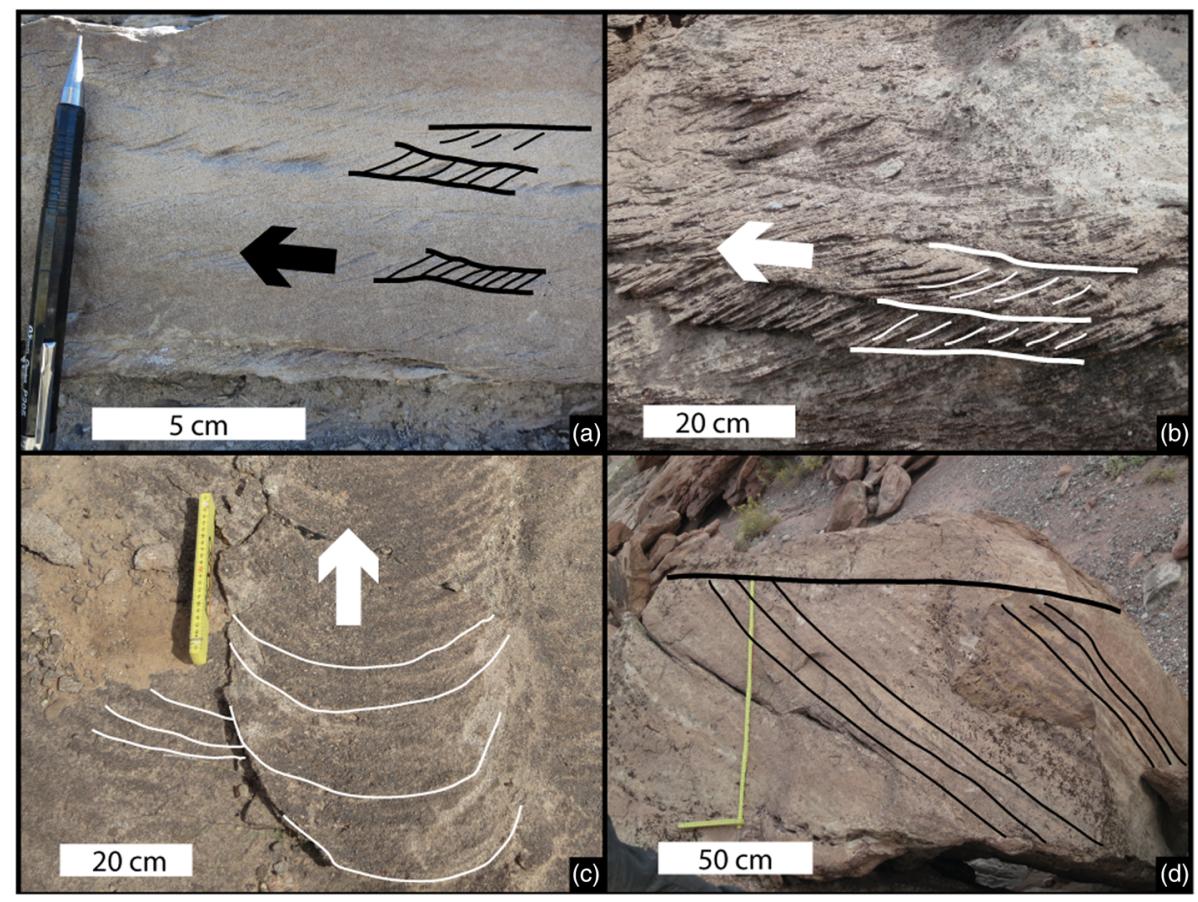

Figure 6. Examples of sedimentary structures observed in the field sites, arrows indicate paleo-flow direction interpreted from accretion direction when applicable. (a) Ripples in Ferron Creek North; (b) truncated dune cross strata in Ferron Creek North. (c) Rib-and-furrow structures (plan view expression of dune trough cross strata); (d) truncated bar clinoforms in Ferron Creek North.

a tape measure or laser range finder and corrected the measurements to be perpendicular to the paleo-flow direction for comparison to the eroded widths and thicknesses of the ridges.

\section{Paleo-Hydraulic Methods}

In situ sedimentological observations on Mars are limited, and therefore we need methods to link paleo-river channel geometries to attributes of ridges measurable from orbit (e.g., Burr et al., 2010; Goudge et al., 2018; Hayden et al., 2019; Jacobsen \& Burr, 2018; Kite et al., 2015). We used classic methods in sedimentology to reconstruct likely channel dimensions for the Morrison ridges, following Hayden et al. (2019), and we compared the results to methods based on ridge geometry. The ridge geometry methods we evaluated included relating caprock thickness to paleo-channel depth (DiBiase et al., 2013; Hayden et al., 2019) and relating ridge caprock breadth to paleo-channel width (Burr et al., 2010; Kite et al., 2015; Williams et al., 2013). We also evaluated using the radius of curvature of the ridges and of exposed LAS surfaces, which, along with ridge wavelength, have been used extensively on Mars (Burr et al., 2010; Goudge et al., 2018; Kite et al., 2015, 2019; Moore et al., 2003; Williams et al., 2013).

\subsection{Paleo-Hydraulics From Sedimentary Structures}

We consider the sedimentology paleo-hydraulic reconstruction to be the most accurate, because it has been well tested and used for decades (Allen, 1963; Hajek \& Heller, 2012; Mohrig et al., 2000). Following Hayden et al. (2019), this method uses cross stratification from bar clinoforms (Figure 6d) or dune cross strata (Figure 6b) as indicators of bankfull channel depth. Bars are the preferred depth indicator because, where bar strata are not truncated, the bar clinoform thickness $\left(t_{b}\right)$ is approximately equal to the bankfull channel depth $(d)$ (Hajek \& Heller, 2012; Mohrig et al., 2000):

$$
d / t_{b}=1
$$

Mohrig et al. (2000) found bounds in Equation 1 of $0.3-2.5$ for individual measurements from the modern North Loup River, so we estimate that the uncertainty on the mean of a suite of measurements is a factor of 2 . 
Dunes also scale with flow depth (Bradley \& Venditti, 2017); however, dune cross stratification is typically truncated, leaving dune set thicknesses $\left(t_{d}\right)$ that are a fraction of the dune heights (Leclair \& Bridge, 2001; Paola \& Borgman, 1991). Combining the mean relationship between dune height and channel depth for small rivers ( $d$ is 3.5 times dune height with a range of 2.1-9.9, for $d<2.5 \mathrm{~m}$ ) of Bradley and Venditti (2017) with the mean relationship between dune set thicknesses and dune heights (dune heights are 2.9 times $t_{d}$ with a range of 2.2-3.6) from Leclair and Bridge (2001), we found

$$
d / t_{d}=10.2 \text { (bounds:4.7-18.7) }
$$

Using the small-river data of Bradley and Venditti (2017) is consistent with flow depths we interpret from the bars in our field area.

In addition to channel depth, the other parameters needed to calculate water discharge $(Q)$ are channel width $(w)$ and mean flow velocity $(U)$, following mass balance (i.e., $Q=w d U$ ). Single-thread rivers tend to all have similar width-depth ratios, and we used the median and 5th-95th percentile range of the Trampush et al. (2014) global compilation of bankfull geometry as follows:

$$
w / d=18 \text { (bounds: } 8.4-53)
$$

Width-depth ratios for braided rivers are higher than for single-thread rivers (e.g., van den Berg, 1995), so Equation 3 underestimates width for braided paleo-channels.

To get flow velocity $(U)$, we used the flow resistance method of Engelund and Hansen (1967) that is based on partitioning hydraulic roughness in sand-bedded rivers between the bed sediment (skin friction) and drag from bedforms (Einstein, 1950):

$$
U=\frac{1}{\varkappa} \ln \left[11 \frac{R D_{50}}{S k_{s}} \tau_{*_{s}}\right]\left(\operatorname{Rg} D_{50} \tau_{*_{S}}\right)^{0.5}
$$

where $\kappa=0.41$ is von Karman's constant, $R$ is the submerged specific density of the sediment $(R=1.65$ for quartz in water), $D_{50}$ is the median grain size, $S$ is the bed slope, $k_{s}=2.5 D_{50}$ is the grain roughness lengthscale, and $g$ is the acceleration of gravity. $\tau_{*_{s}}$ is the skin friction component of the Shields stress calculated from $\tau_{*_{s}}=0.06+0.4 \tau_{*}^{2}$ (Engelund \& Hansen, 1967), where $\tau_{*}$ is the total Shields stress $\left(\tau_{*}=d S /\right.$ $R D_{50}$ assuming steady and uniform flow). In paleo-hydraulic applications where slope is not known a priori, $\tau_{*}$ can be calculated from the empirical Trampush et al. (2014) relationship recommended by Hayden et al. (2019):

$$
\tau *=17 R e_{p}^{-0.5}
$$

where $R e_{p}$ is the particle Reynolds number $R e_{p}=\left(\operatorname{Rg} D_{50}\right)^{0.5} D_{50} / \nu$ and $\nu$ is the kinematic viscosity of water. Slope is then obtained from Equation 5 and the normal-flow approximation. Combining these equations gives an expression for bankfull river discharge (Hayden et al., 2019):

$$
Q=74.2 C_{f}^{-1 / 2}(R g)^{3 / 8} v^{1 / 4} D_{50}^{1 / 8} d^{2}
$$

where $C_{f}=U_{*}^{2} / U^{2}$ is the friction coefficient, $U_{*}^{2}=\tau * / \operatorname{Rg} D_{50}$ is the shear velocity, and $U$ can be computed from Equation 4 following the method of Engelund and Hansen (1967). To use Equation 6, there are two inputs from field measurements: flow depth constrained from dune or bar cross strata (Equations 1 and 2) and median grain size.

The major source of uncertainties in applying Equation 6 is in the reconstructions of paleo-channel depth (a factor of 2 from Equations 1 or 2), channel width (a factor of 2.5; Equation 3), and bed shear velocity (a factor of 5 uncertainty from Equation 5). Combining these factors with Gaussian error propagation assuming lognormal distributions on each parameter, we estimate uncertainty on Equation 6 to be a factor of 9. Despite high uncertainty, we prefer this physics-based method to prior empirical methods, such as scaling channel width to discharge (e.g., Williams, 1988), because it identifies all important variables and explicitly accounts for material properties and gravity that may be different on Mars. 


\subsection{Ridge Caprock Thickness as a Proxy for Channel Depth}

In addition to the sedimentology method (section 4.1), we evaluated paleo-hydraulic tools to estimate channel size and discharge based on ridge properties alone, since ridge bar and dune strata cannot readily be observed on Mars from orbit. Hayden et al. (2019) proposed that caprock thickness for fluvial ridges can be used as a proxy for bankfull paleo-channel depth due to the tendency of a channel to abandon its course after aggrading by an amount that scales with channel depth (Bryant et al., 1995; Ganti, Chu, et al., 2014; Ganti, Lamb, et al., 2014; Ganti et al., 2016; Hajek \& Wolinsky, 2012; Jerolmack \& Swenson, 2007; Mohrig et al., 2000; Slingerland \& Smith, 2004). Erosion and amalgamation by subsequent reoccupations of the same channel position can modify the relation to channel depth, but Hayden et al. (2019) found tight constraints on the relationship between caprock or channel-belt thickness $(T)$ and paleo-channel depth $(d)$ using a compilation of channel-belts worldwide and ridges in the Cedar Mountain Formation,

$$
T / d=1.5(5 \text { th-95th percentile bounds:0.8-4) }
$$

Equation 7 can be used in conjunction with Equation 6 to calculate discharge in the absence of constraints on dune or bar cross strata thicknesses. The bounds in Equation 7 yield a similar level of uncertainty (a factor of 2) as Equations 1 and 2. If grainsize is also unknown, as is the case for most ridges on Mars, end-member sand- and gravel-bedded scenarios can be used. Due to the low power on $D_{50}$ in Equation 6, the discharge varies by a factor of only 1.9 across the two dominant modes in $D_{50}$ observed on Earth: medium sand $(0.3 \mathrm{~mm})$ and medium gravel $(50 \mathrm{~mm})$ (Trampush et al., 2014). We view all grainsizes within this range as equally likely, so we take the geometric mean of the bounds (3.9 mm) as a central estimate for Equation 6. The uncertainty in using Equation 6 with unknown grainsize therefore is the product of uncertainty in Equation 6 and uncertainty in grainsize around the central estimate (1.4; from $\sqrt{1.9})$ - a factor of 12 .

\subsection{Radius of Curvature of Ridges and LAS}

Median radius of curvature $(C)$ of multiple channel bends scales with channel width for meandering rivers (e.g., Hickin, 1978; Nanson, 1980; van de Lageweg et al., 2014). The relationship commonly used comes from Williams (1986, 1988),

$$
w=0.71 C^{0.89}
$$

Assuming channel inversion, Equation 8 (or a similar one relating width and planform wavelength) has been applied to ridges on Mars when ridge centerlines are interpreted to reflect paleo-channel centerlines (e.g., Burr et al., 2009; Jacobsen \& Burr, 2018; Jerolmack et al., 2004; Moore et al., 2003).

For exhumed and eroded channel-belt deposits, it is unlikely that ridge centerlines track paleo-channel centerlines. Instead, the radius of curvature of LAS, where observed, should be a better representation of the curvature of the inner bank of a channel (i.e., $C_{\text {inner }}=C_{L A S}$ ). To apply Equation 8 to channel-margin curvature, we fitted a power law to the original Williams (1986) data (widths: $10^{0}-10^{3}$ ) between channel width and the radius of curvature of the inner bank. We estimated the radius of curvature of the inner bank as $C_{\text {inner }}=C-w / 2$ under the assumptions that the banks are parallel to the centerline and the bend can be represented as part of a circle. The exponent was within a standard deviation of one, so we forced it to one to make the equation dimensionally correct and found

$$
w=0.5 C_{\text {inner }}
$$

Goudge et al. (2018) assumed the same relation in reconstructing paleo-channel width at Jezero Crater from LAS traces.

To find discharge using curvature of the ridge centerline or LAS as constraints, we used Equations 8 or 9 to estimate channel width, Equation 3 to calculate channel depth, and then used depth to find discharge using Equation 6, assuming a range in possible $D_{50}$ as described in section 4.2. We estimated uncertainty in Equations 8 or 9 as similar to that in Equations 1, 2, or 7 (a factor of 2), so the total uncertainty in reconstructing discharge from curvature is also interpreted to be 9 or 12 for known or unknown grainsize, respectively. 


\subsection{Ridge Width}

Ridge width has been used in the past to directly infer channel width (e.g., Burr et al., 2010; Kite et al., 2015). However, more recently, this proxy was evaluated extensively by Hayden et al. (2019) and they showed that ridge width can deviate significantly from channel widths (by factors $>30$ ) if ridge caprocks are channel-belt sandstones that have been built through lateral accretion and amalgamation and later narrowed by erosion during exhumation to form a ridge. The controls on ridge width narrowing due to erosion is a topic we revisit herein in the Morrison Formation for ridges that can be traced into cliff-outcrop exposures where the uneroded channel belt can be observed (section 6.2).

\section{Results}

\subsection{FCN}

The FCN site contains seven ridges in the Brushy Basin Member and is notable for the five ridges (Ridges A, $\mathrm{B}$, and $\mathrm{E}-\mathrm{G}$ ) that extend into cliff outcrops where the nonexhumed sandstone bodies are exposed in full cross sections (Figures 7a and $7 \mathrm{~b}$ ). The ridges are composed of sandstone caprocks 1-6 $\mathrm{m}$ thick and 9-30 $\mathrm{m}$ wide that all overlie mudstone. The tectonic-dip-corrected DEM (Figure 7a) shows the caprocks are at four stratigraphic levels: Ridge $\mathrm{A}$ is above Ridge $\mathrm{B}$, which in turn is above Ridges $\mathrm{C}$ and $\mathrm{D}$, and Ridges $\mathrm{C}$ and $\mathrm{D}$ are above Ridges $\mathrm{E}-\mathrm{G}$ (Figures $7 \mathrm{~b}$ and $7 \mathrm{c}$ ). Field observations at ridge crossings confirm these relationships; there are mudstones that separate the sandstone caprocks of crossing ridges indicating that the sandstone bodies are at distinct stratigraphic levels (Figures 8 and 9). Best-fit caprock slopes running along the ridges, after removing tectonic tilt, range from $10^{-5}$ to $10^{-2}$ (Figure 7c), and all ridges have relief $2-10 \mathrm{~m}$ above the surrounding terrain (Figure $7 \mathrm{~d}$ and SI Table S1). The slopes of individual flanks range $1-70^{\circ}$. Ridges only have a few bends, and the radius of curvature for ridge centerlines range from 40 to $100 \mathrm{~m}$ for Ridges A, $\mathrm{B}$, and $\mathrm{E}$ (Figure $7 \mathrm{~b}$ ).

Caprocks are composed of medium sandstone with cross stratification (Figure 6). Dune cross strata, identified by their height and trough shape in cross section and rib and furrow structure in plan view, ranged in height from 10 to $40 \mathrm{~cm}$ and indicated flow directions that generally paralleled the local ridge axes (Figure 7a). One structure in Ridge B was $1 \mathrm{~m}$ in height, had an accretion direction perpendicular to the ridge axis, and had planar cross strata, so it was interpreted as a laterally accreting bar (Figure 7a). A similar structure was observed on the edge of Ridge A. Mudstones underlie all caprocks and contain sparse, thin sandstone beds with thicknesses ranging from 1 to $50 \mathrm{~cm}$ (Figures 8 and 9).

Based on similar elevations (Figure 7c), caprock thicknesses (Figure 7d), and paleo-flow directions (Figure 7a), we interpret the caprocks of Ridges $\mathrm{C}$ and D to be segments of the same sandstone body. Similarly, we interpret Ridges E-G to be segments of the same sandstone body.

Ridge A extends from the large cliff on the northwest of the field area allowing direct observation of the equivalent material that surrounded the ridge and was removed during exhumation (Figure 8). At the cliff face, the sandstone body that composes the ridge caprock is uneroded, $100 \mathrm{~m}$ wide, and $4 \mathrm{~m}$ thick. At the edge of the sandstone body, we observed thickening and subsequent thinning of the sandstone, which we interpret as levees, with internal S-shaped stratification that we interpret as bar clinoforms. Thin sandstone beds or wings (Mohrig et al., 2000) thin away from the core of the body (Figure 8) and interfinger into the neighboring mudstone. The wing sandstone beds contain climbing ripple strata, indicating paleoflow away from the sandstone body. This geometry matches observations of other channel belts in which the wings formed from overbank deposition (e.g., Chesley \& Leier, 2018; Mohrig et al., 2000). From the cliff exposure to the ridge terminus $170 \mathrm{~m}$ from the cliff, ridge breadth decreases from 100 to $10 \mathrm{~m}$, ridge relief increases from 0 to $13 \mathrm{~m}$, mean ridge flank slope increases from nonexistent to a final value of $29^{\circ}$, and caprock thickness remains approximately constant at 3-4 m (Figure 8e). From comparison to the cliff outcrop exposure, most of the ridge is composed of only the center of the sandstone body; the neighboring mudstone, thinner sandstone wings, and margins of the sandstone body have been completely eroded away during ridge formation. Blocks of the sandstone body now make up talus on the ridge flank (Figure 8). Further support for the interpretation of ridge narrowing comes from a pedestal of mudstone with a $70 \mathrm{~cm}$ thick sandstone block at the top, located $20 \mathrm{~m}$ to the side of the Ridge A (Figure $8 \mathrm{~b}$ ). The pedestal sandstone is of comparable thickness, at the same stratigraphic level, and contains similar 


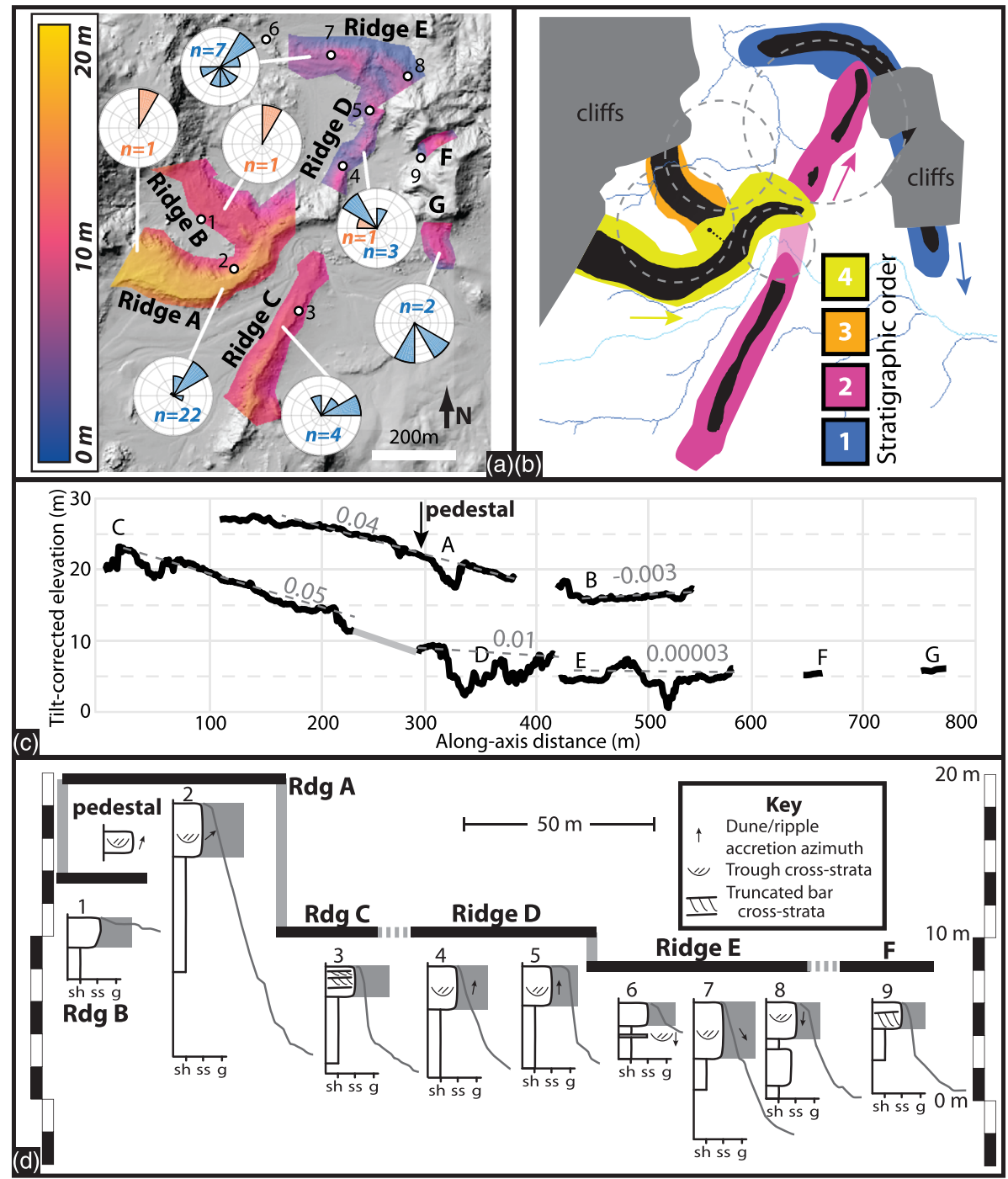

Figure 7. Ferron Creek North (FCN) site. (a). Map of field area with each ridge highlighted; colors represent height in stratigraphic models (DEM rotated to remove tectonic dip). Colored regions highlight ridge caprocks and flank slopes. Numbers are stratigraphic sections. Rose diagrams represent accretion direction of bar sets (red) and paleo-flow directions interpreted from dune trough cross stratification (blue) within the ridge caprocks; $n$ is the number of observations made along the ridge caprock. Background image is the hillshade of the lidar DEM. (b) Interpretation of ridge superpositions shown in panel a, with same scale. Ridge caprocks are indicated in black, ridge flanks are indicated in dark colors, and semitransparent portions indicate interpreted ridge connections. Interpreted paleo-flow direction indicated in a colored arrow next to the ridge. Modern washes given in branching blue networks. Black dot connected by a dotted line to the yellow ridge (Ridge A) is the pedestal described in the text. Gray dashed circles are the locations where radius of curvature of the centerline was measured. (c) Elevation profiles along ridge axes corrected for tectonic tilt, with the caprock top given in black lines, interpreted connections given in gray lines. Dashed gray lines indicate bestfit topographic slope. (d) Representative stratigraphic sections (numbers indicate location on panel a; shale, sandstone, and gravel indicated by sh, ss, and g, respectively), with cross stratification noted. Also included (thick gray, sloping lines) are the cross-sectional profiles off the side of the ridge; note that for many of them, there is a break in slope coincident with caprock though in other places the slope break is less obvious due to erosion and talus accumulation (Figures 8 and 9). Vertical exaggeration $\sim 5$ times; scale bar only applies to topographic transects in this panel. Lines at the top highlight caprocks of similar stratigraphic position; black solid lines are on the same ridge, and gray dotted lines indicate an interpreted tie line.

sedimentary structures and paleo-current directions as the caprock of Ridge A (Figure 7). Thus, we interpret the pedestal sandstone to be a remnant of the once much wider former extent of the Ridge A caprock sandstone body (Figures $8 \mathrm{~b}$ and $8 \mathrm{e}$ ). 


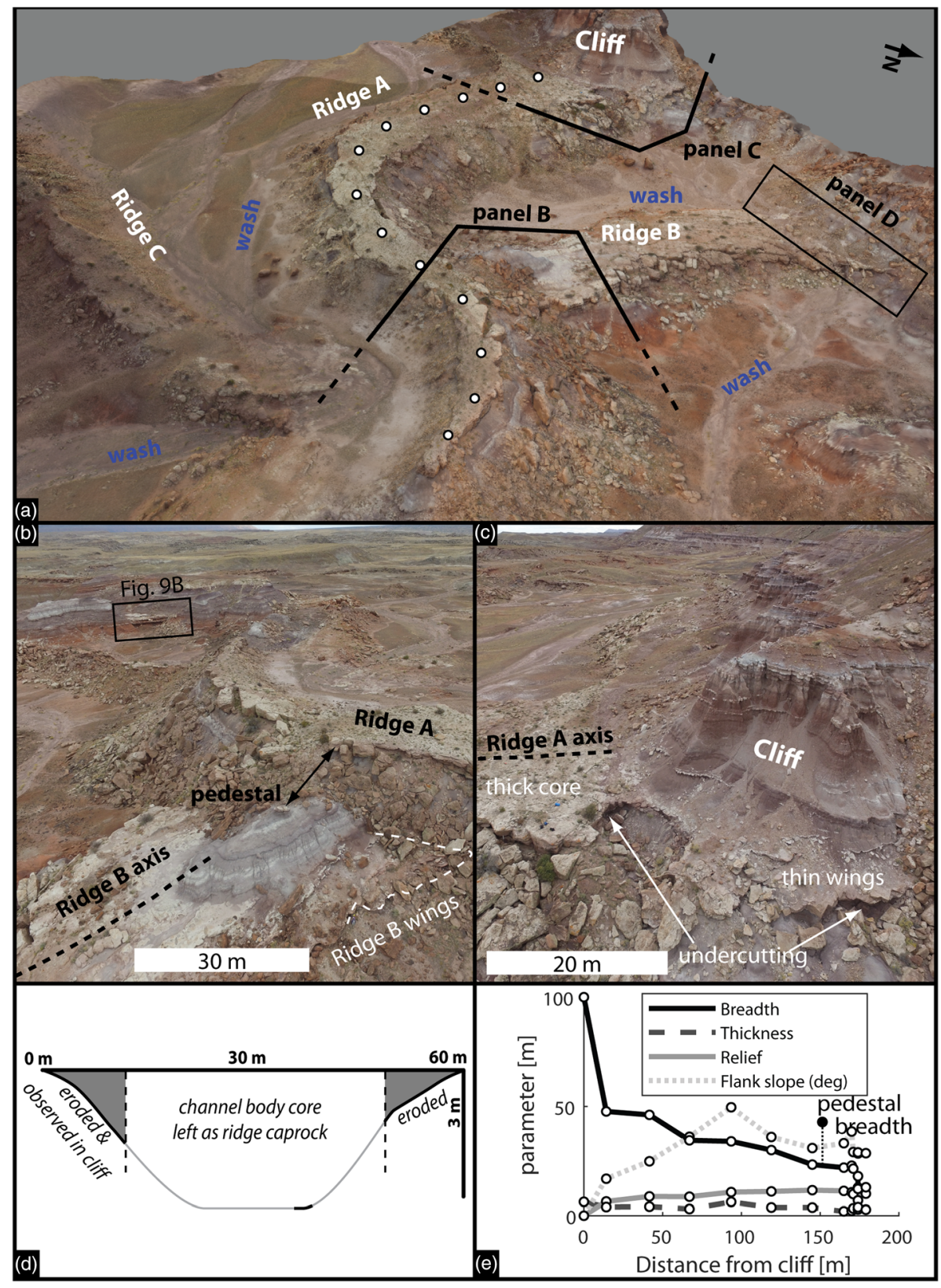

Figure 8. Ridge A exemplifies many of the characteristics we observe for ridges throughout the field site. (a) Oblique view of Ferron Creek North site in 3-D model created in Agisoft Metashape from quadcopter photos (view to southwest from near stratigraphic section \#4 on Figure 7a). Ridge A is widest near the cliff (top of the panel) and narrows further away until there is no ridge caprock left (bottom of the panel). White dots indicate data positions for panel (e). (b) Quadcopter photo looking NE from near \#1 on Figure 7a, showing that Ridge A superposes Ridge B with mudstone between them and significant talus cover on the flanks. There is a remnant pedestal located $20 \mathrm{~m}$ to the side of Ridge A. Ridge B has wings that can be observed in the mudstone under the caprock of Ridge A. (c) Quadcopter photo looking perpendicular to the axis of Ridge A from near \#1 on Figure 7a, showing thin wings on the side of the ridge that can be observed in the cliff. The thin wings are eroded along the rest of the ridge, leaving only the thicker central core. (d) Reconstructed geometry of the uneroded caprock for Ridge B based on observations made of exposures of the wings and within cracks in the caprock that allow us to sample the caprock thickness (black line in lower right corner). Black outlines are observed thicknesses, and gray outlines are inferred. (e) Geometry of FCN Ridge A as a function of distance from the cliff exposure where it is uneroded. The pedestal is the caprock remnant to the north of Ridge A (panel b), and the breadth indicated by that point on the figure indicates the width of Ridge A if it extended to the pedestal. 


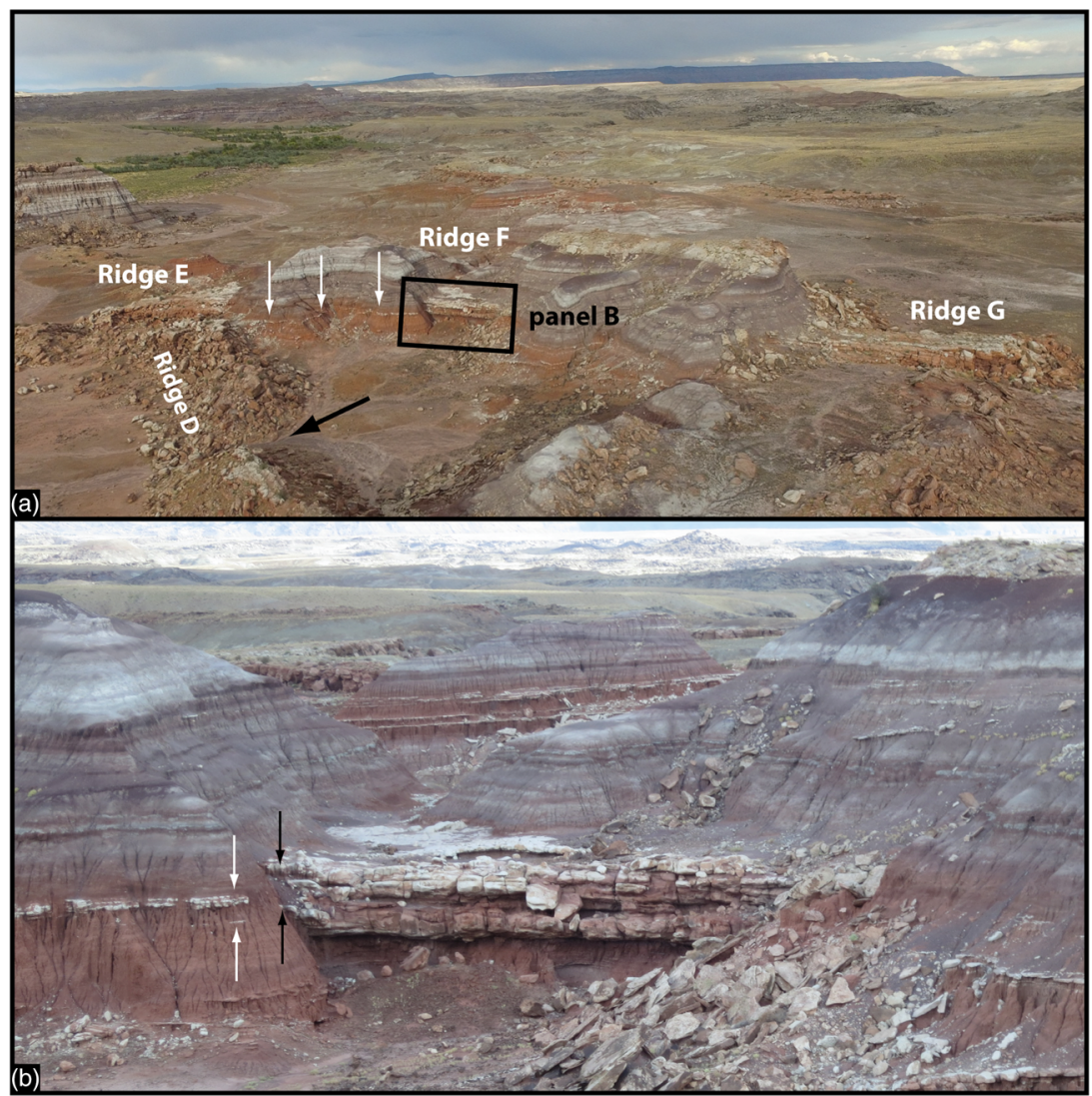

Figure 9. Quadcopter photos of Ferron Creek North looking northeast to Ridges D-G. (a) Ridges E-G all emerge from a series of cliffs, indicating they are exhumed from the mudstone and likely represent a single continuous channel body. The mudstone cliffs with only minimal sandstone visible demonstrate that the channel body is laterally narrow. White arrows trace the upper white sandstone layer shown in panel b. Black arrow indicates where Ridge D is segmented by a wash, with the caprock remnants collapsed into the wash. (b) Looking east at Ridge F, emerging from two cliffs. Paleo-flow in the channel body is to the right on the image. Note that the channel body, while eroded and undercut in the image center, likely did not extend much farther toward the foreground because the caprock thins significantly from the black arrows to the thin "wing" sandstone sheets given by white arrows over $<10 \mathrm{~m}$ lateral distance.

Ridge B also emerges from the large cliff, and its other end terminates under Ridge A (Figure 8). The ridgecapping sandstone body is widest at these outcrops (60 m) and narrows away from the outcrops (to $30 \mathrm{~m}$ ). Thickness varies between 3 and $5 \mathrm{~m}$ and is uncorrelated with distance from the outcrops. Similar to Ridge A, the sandstone body at Ridge B, where fully preserved at the outcrops, has thin sandstone wings with climbing-ripple cross stratification indicating paleo-flow away from the caprock (Figure 8). The wings and channel-body margins are not preserved in the middle of the ridge.

The capping sandstones for Ridges E-G also are fully exposed in cliff outcrops (Figure 9). In cliff exposures, we measured the width of Ridge $\mathrm{E}$ to be $30 \mathrm{~m}$ and observed Ridges $\mathrm{F}$ and $\mathrm{G}$ to have two sets of wings that align with two stacked sets of $\sim 1 \mathrm{~m}$ thick LAS in the channel body (Figure 9b). Importantly, the escarpment erosion around Ridge $\mathrm{F}$ allows observations of the finite width of the caprock sandstone body and the lateral transition to floodplain facies (Figure 9b).

Other indicators of erosion include recessive erosional niches in the mudstone underlying ridge caprocks (Figures 8 and 9) and abundant talus on flank slopes made up of blocks of caprock sandstone (Figures 8 and 9). Caprock tops exhibit rib and furrow structures and caprock sides exhibit cross strata, indicating that erosion has removed some material vertically and laterally. Caprock sandstone bodies are $>1.5 \mathrm{~m}$ thick (Figure 7d), suggesting thinner sandstone bodies are more rapidly eroded during exhumation. Finally, we note that the presence of numerous washes that tend to flow alongside the ridges. In some cases, washes 
cross ridges and erode them: Ridge $\mathrm{D}$ has been segmented by a wash (note the missing caprock in Figures $7 \mathrm{~b}$ and 9a), and Ridges B and C have washes crossing them (Figure $7 \mathrm{~b}$ ).

\subsection{FCS}

The FCS site contains three ridge segments in the Salt Wash Member and is notable for LAS visible in plan view (Ridge B; Figures 10 and 11). Two shorter ridges (A and C) cross over a longer one (B), and the tilt-corrected elevation model shows that Ridges $\mathrm{A}$ and $\mathrm{C}$ are at a similar stratigraphic position, about $3 \mathrm{~m}$ higher than Ridge B (Figures 10a and 10b). Field observation indicates mudstone between the caprocks of Ridge B and the overriding Ridges A and C (Figure 11d). Based on similar elevations (Figure 10c), caprock thickness (Figure 10d), and paleo-flow directions (Figure 10a), we infer that Ridges A and C are part of the same sandstone body (Figure 10b).

Best-fit caprock slopes range $0.03-0.08$ after removing tectonic tilt, relief ranges from 4 to $14 \mathrm{~m}$, and caprock thickness varies from 1.5 to $8.4 \mathrm{~m}$ (Figures 10c and 10d; SI Table S1). Caprock breadth varies from 10 to $70 \mathrm{~m}$, with variation dominated by a periodic widening at portions that exhibit LAS with narrowing between those locations (Figures 10a and 10b). Radius of curvature of ridge centerlines varies from 90 to $170 \mathrm{~m}$ at different bends.

The caprocks are made up of medium sandstone, with some gravel up to $1 \mathrm{~cm}$ diameter observed in Ridge B. Several types of inclined stratification were observed (Figures 6c, 10d, and 11). Dune trough cross sets were observed to be $10-40 \mathrm{~cm}$ in height and, in some cases, contained ripple cross strata (Figure 11e; SI Table S2). The dune sets had accretion directions indicating paleo-flows in similar directions to the ridge axes (Figure 10a). Unlike FCN, channel-belt wings were not observed at FCS nor were cliff exposures available to verify original sandstone body thicknesses. Instead, this site showed abundant large ( $>1 \mathrm{~m}$ thick), planar sets of inclined strata that extended laterally for tens of meters, with accretion directions approximately perpendicular to inferred paleo-flow direction from dune cross strata (Figures 10a and 11d). We interpreted the larger, planar sets as resulting from bank-attached laterally accreting point bars (i.e., LAS). Field observations show that the semiconcentric curved lines visible from orbital images are traces of LAS beds as they intersect the eroding land surface (Figures 11a-11c). The inclined beds are up to $20 \mathrm{~cm}$ in thickness and tend to erode along bedding planes, such that individual beds make small ridges that protrude from the ridge top. LAS traces had radii of curvature varying from 70 to $140 \mathrm{~m}$, slightly smaller than the ridge centerlines (SI Table S3).

Like the FCN site, here there is abundant evidence for ridge erosion due to scarp retreat. Mudstone flanks are covered in large (up to $12 \mathrm{~m}$ diameter) talus blocks, with the largest and most abundant blocks on the highest relief flanks (e.g., near the bank-attached bar on Ridge B; Figure 11). Evidence of vertical degradation comes from the exposed LAS and other exposed strata on ridge tops (Figure 11).

\subsection{WHM}

The WHM site contains three ridges in the Salt Wash Member and is notable for two lower ridges visibly outcropping from under a higher ridge (Figures 12 and 13). Using the tilt-corrected DEM, we observed that the ridges span $50 \mathrm{~m}$ of stratigraphy and the upper ridge (Ridge A) caprock is $15 \mathrm{~m}$ higher than the lower ridge caprocks (Ridges B and C), which are at approximately the same stratigraphic level (Figure 12). Tectonic-corrected slopes for the ridge tops range from 0.02 to 0.05 , and relief ranges between 4 and 32 $\mathrm{m}$ (Figure 12). Caprock thickness varies from 2 to $9 \mathrm{~m}$ (Figure 12d), and bend radius of curvature of the ridge centerline varies from 280 to $340 \mathrm{~m}$ (Figure 12b and SI Table S3). Breadth varies from 10 to $74 \mathrm{~m}$ (Figures 12a and 12b and SI Table S1), with the narrowest portions of each ridge being at the ridge ends (e.g., south end of Ridge B; Figure 12b) or at a crossing of a modern wash (e.g., west end of Ridge C; Figure 12b).

Caprocks are dominantly composed of medium sandstone with some gravels up to $1 \mathrm{~cm}$ in diameter. Caprocks also contain abundant inclined stratification of a variety of types. Dune cross strata have thicknesses 8-41 cm and indicate paleo-flow generally aligning with ridge axes (Figure 12a). Truncated bar clinoforms are up to $2 \mathrm{~m}$ tall, which is smaller than the caprock thickness, suggesting the caprock of Ridge A contains multiple generations of amalgamated deposits. We also observed a laterally extensive set of inclined strata perpendicular to paleo-flow (Figure 13a) that we interpreted as a laterally accreting bank-attached bar strata; though, unlike FCS, here the LAS was not apparent in air photos (e.g., Figure 13b). Based on 


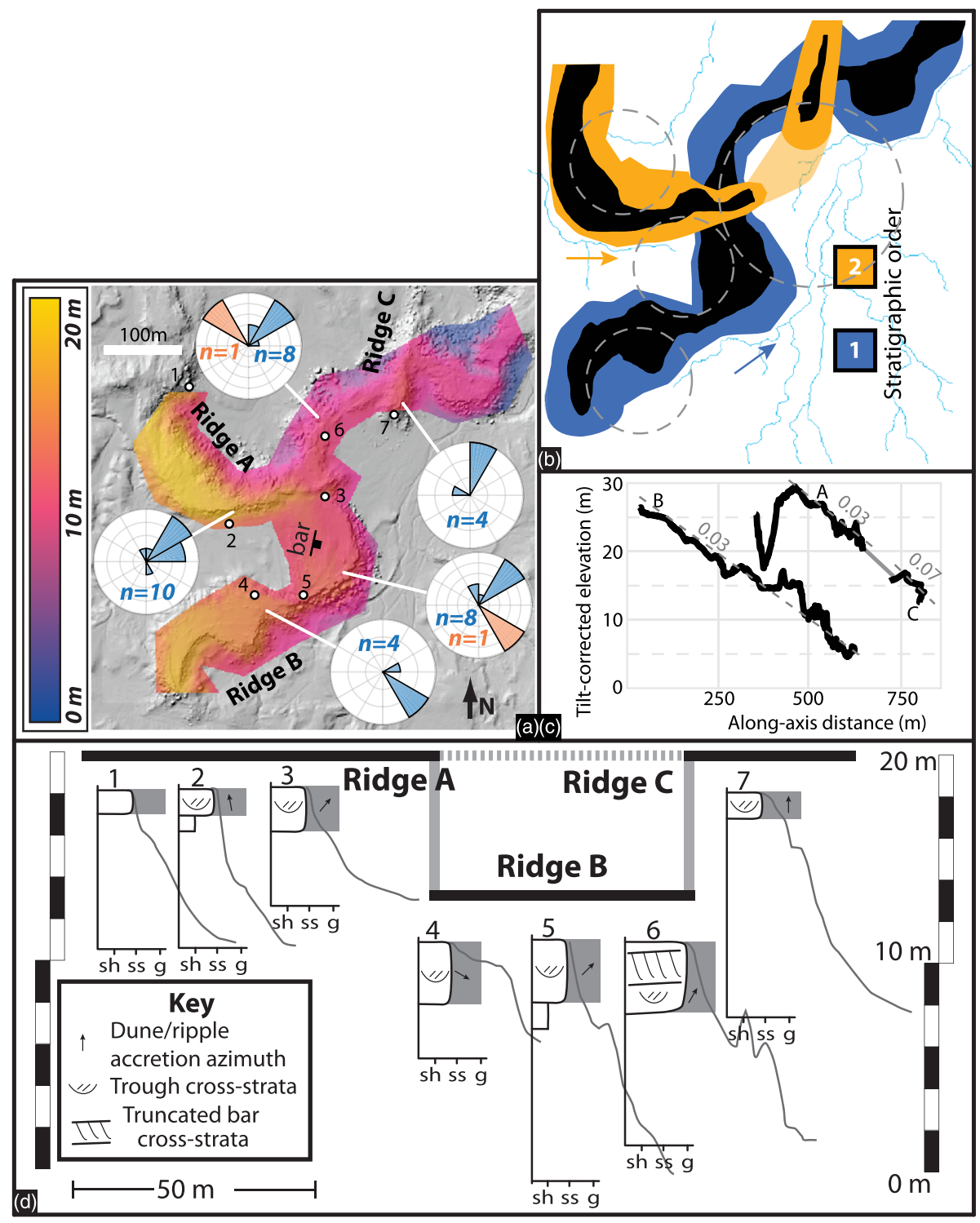

Figure 10. Ferron Creek South site. (a) Lidar digital elevation map: Colors represent height in the stratigraphic model (DEM rotated to remove tectonic dip) and colored regions include the ridge caprock and the flank slopes. Numbers are stratigraphic sections (shown in panel d). Rose diagrams represent accretion direction of bar sets (red) and dune trough cross stratification (blue). (b) Interpretation of stratigraphic positions of ridges, shown at same scale as panel (a). Ridge caprocks are indicated in black, and ridge flanks are indicated in dark colors. Interpretations of ridge connections in transparent colors. Interpreted paleo-flow indicated in a colored arrow next to the ridge it represents. Modern washes are given in branching blue networks. Gray dashed circles are the locations where radius of curvature of the centerline was measured. (c) Ridge elevation profiles taken from the dip-corrected DEM along each ridge top centerline (black lines). Gray line indicates inferred connection between Ridges A and C. Dashed gray line indicates bestfit line used to calculate ridgetop slope. (d) Representative stratigraphic sections (numbers indicate location on panel a; shale, sandstone, and gravel indicated by sh, ss, and g, respectively), with cross stratification noted. Thick gray, sloping lines are the elevation profiles off the side of the ridge. Vertical exaggeration $\sim 5$ times; scale bar only applies to topographic profiles (gray lines) in this panel. Bold black horizontal lines show interpreted stratigraphic position and gray dotted lines represented interpreted tie lines between ridges.

alignment, proximity (Figures 12a and 12b), similar elevations (Figure 12c), and caprock thicknesses (Figure 12d), we interpret the caprocks of Ridges B and C to be segments of the same sandstone body running continuously underneath Ridge A. Mudstone was observed to separate the caprocks at the crossing locating (Figure 13b). 


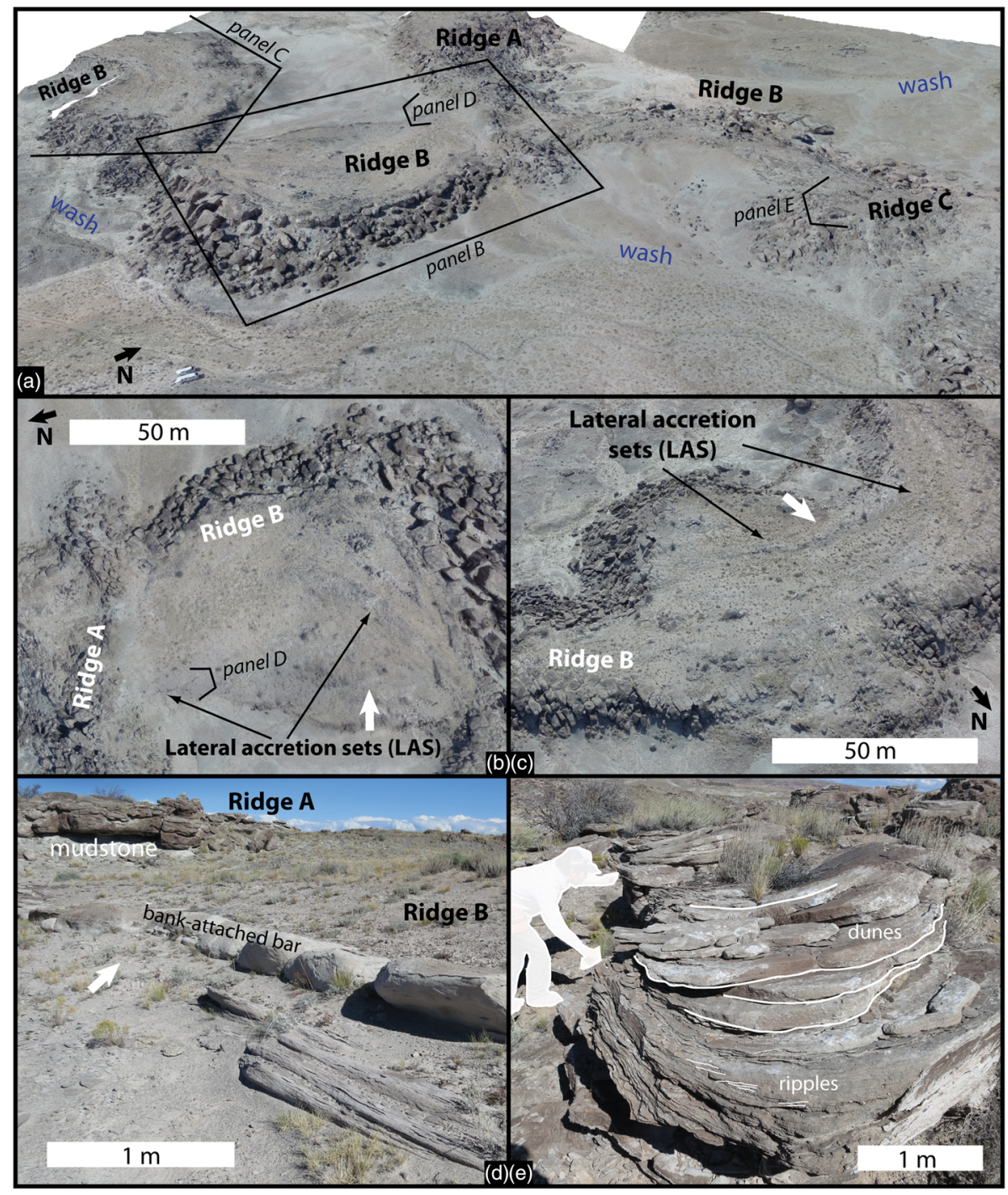

Figure 11. Field photos of Ferron Creek South site. (a) The 3-D model of the field site made in Agisoft Metashape from quadcopter photos. View is to the southwest, field vehicles in the lower left for scale. All ridges have talus-covered flanks. Ridge B contains lateral accretion sets, interpreted as a point bar. Locations of other panels are shown. (b) The 3-D model zoomed in on Ridge B, showing a closer view on some of the curving lateral accretion sets, with an accretion direction indicated by the white arrow. Location of panel $d$ is shown. (c) Oblique quadcopter view of another portion of Ridge B, showing lateral accretion sets with an accretion direction indicated by the white arrow. (d) Image on the top of Ridge B, showing eroded, outcropping, planar beds that make the LAS traces observed from areal imagery. LAS accretion directions (white arrow) are perpendicular to the paleo-flow direction inferred from superimposed dune-scale trough cross strata (Figure 10a), consistent with point-bar strata. Ridges A and B are separated by mudstone (upper left of the left panel). (e) Dune sets with internal ripples on Ridge B; view toward the northeast.

Ridge flanks are armored with caprock talus blocks that are up to $10 \mathrm{~m}$ in diameter, indicating extensive lateral erosion of the caprock (Figure 13b). Washes follow the topographic slope to the south and divert around ridges. One wash crosses Ridge $\mathrm{C}$ near its intersection with Ridge $\mathrm{A}$, and has visibly narrowed the caprock (Figure 12b). A similar notching is seen in Ridge B near its intersection with Ridge A (Figure 13b) but that ridge is taller and so the current washes flow around the outside.

\subsection{Summary of Data and Paleo-Hydraulics From All Sites}

Figure 14 summarizes medians and 5-95 percentiles for ridge dimensions, sedimentological observations, and resultant paleo-hydraulic reconstructions for the Morrison Formation ridges we studied at FCN, Ferron FCS, and WHM. All data are also given in supporting information Tables S1-S3. Grain size of the 


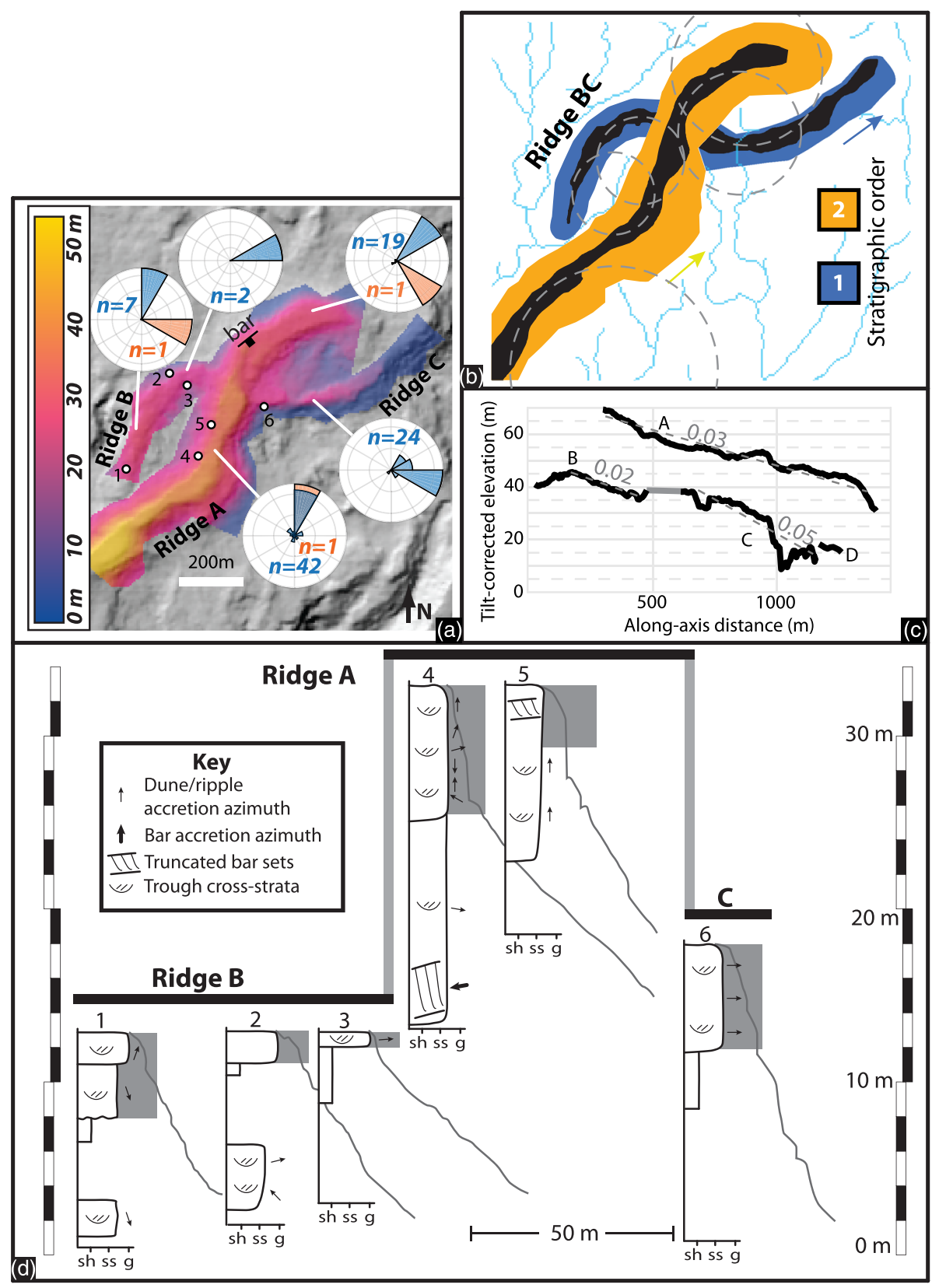

Figure 12. Wild Horse Mesa site. (a) Colors represent height of the ridges and their flanks in the stratigraphic model (DEM rotated to remove tectonic dip). Numbers are stratigraphic sections (shown in panel d). Rose diagrams represent accretion direction of bar clinoforms (red) and dune trough cross stratification (blue). Location marked "bar" is shown in Figure 13. (b) Interpretation of stratigraphic positions of ridges, shown at same scale as panel (a). Ridge caprocks are indicated in black, ridge slopes and ridges lacking caprock are indicated in dark colors, interpreted paleoflow direction indicated in a colored arrow next to the ridge, and modern washes given in branching blue networks. Gray dashed circles are the locations where radius of curvature of the centerline was measured. (c) Ridge elevation profiles taken from the stratigraphic model along each ridge centerline (black lines). Gray lines indicate inferred connection between Ridges B and C. Dashed gray line is a best-fit line used to calculate ridge top slope. (d) Representative stratigraphic sections (numbers correspond to locations on panel a; shale, sandstone, and gravel indicated by sh, ss, and $\mathrm{g}$, respectively), with cross stratification noted. Cross-sectional profiles off the side of the ridge given in gray sloping lines. Vertical exaggeration 5 times; scale bar only applies to topographic profiles (gray lines) in this panel. Bold black horizontal lines show interpreted stratigraphic position and gray dotted lines represented interpreted tie lines between ridges. 


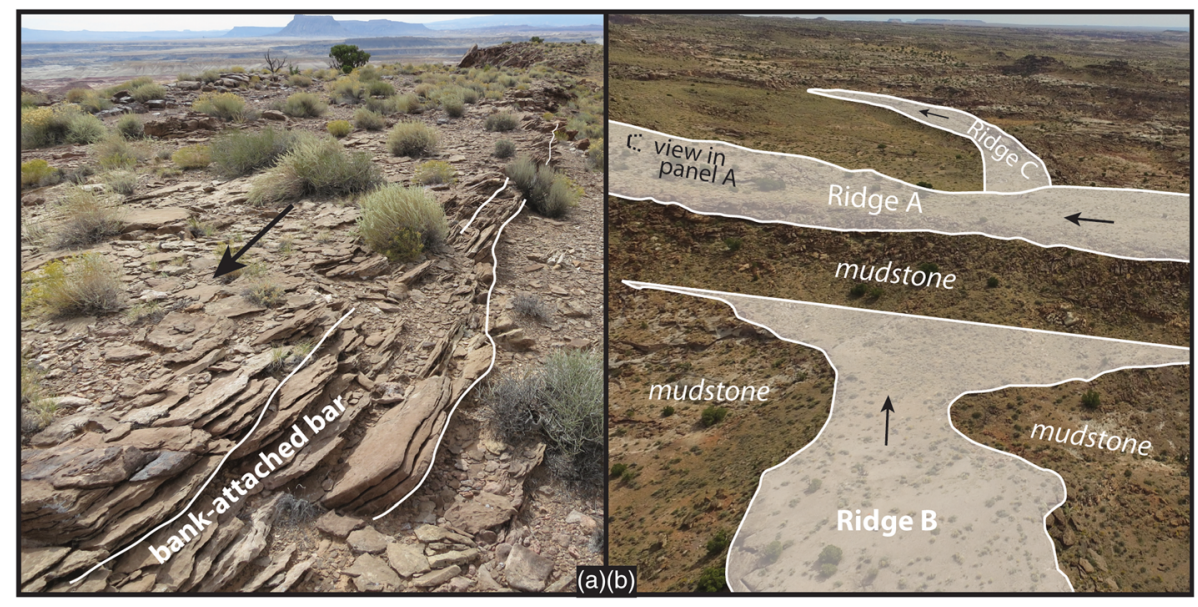

Figure 13. Wild Horse Mesa site. (a) Bank-attached bar strata on top of Ridge A, interpreted from laterally extensive, planar beds with an accretion direction to the southeast (see strike and dip symbol on Ridge A on Figure 12a), perpendicular to the interpreted paleo-flow direction and the ridge axis. (b) Quadcopter image looking east over the ridge intersection. Mudstone occurs below Ridge B and between the caprocks of Ridges A and B.

caprocks (16 observations at FCN, 20 at FCS, and 44 at WHM) varies across the sites with mean $D_{50}$ values for each ridge ranging from fine sandstone to fine gravel, and grain size of noncaprock material ranged from mud to fine sandstone. Set thicknesses and organization indicate caprocks comprise between 1 and 3 generations of amalgamated deposits and, using Equations 1 and 2, are indicative of paleo-flow depths ranging 2.8-5.8 $\mathrm{m}$ based on truncated-bar strata (5 observations at FCN, 2 at FCS, and 4 at WHM) and dune strata (13 observations at FCN, 18 at FCS, and 40 at WHM). Using the methods from section 4.1 for the sedimentological reconstruction, paleo-channel median widths were 50-104 $\mathrm{m}$ and median slopes were 0.0003-0.001. Based on observations of LAS, channel-body wings, and the abundance of mudstone, we interpreted that the paleo-channels were single thread, which is consistent with prior work on the Morrison Formation (Derr, 1974; Heller et al., 2015).

Caprock thickness and breadth and flank relief and slope were all measured in ridge-perpendicular elevation transects, of which we have 38 at FCN, 24 at FCS, and 38 at WHM. In comparison to paleo-channel dimensions reconstructed from sedimentology, ridge relief is far greater than inferred channel depths, but caprock thicknesses are similar. Median relief for each ridge ranges 4-27 m, median caprock thickness ranges 1.5$4.9 \mathrm{~m}$, and median ridge breadth ranges $10-50 \mathrm{~m}$. In cliff exposures where caprock-forming sandstones are uneroded, breadths reach up to $100 \mathrm{~m}$. The measured widths and thicknesses of these uneroded bodies are consistent with values of other uneroded sandstone bodies in the Morrison Formation, which range from 30 to $150 \mathrm{~m}$ breadth and 3.8 to $15 \mathrm{~m}$ thickness (Chesley \& Leier, 2018; Owen, Jupp, et al., 2015; Stokes, 1961). Median radius of curvature of ridge centerlines ranges 70-120 m (four observations at FCN and at WHM and five observations at FCS), and the range of six LAS observed at FCS is 70-140 m. Ridge along-axis slopes are steeper than channel bed slopes inferred from sedimentology by a factor of 10-100. Flank slopes of the studied ridges range $1-70^{\circ}$, with median values for each ridge between $20^{\circ}$ and $30^{\circ}$. Ridge flanks without talus cover fall on the low end of that range, and ridges with more talus cover have steeper slopes.

Paleo-hydraulic reconstructions of depth and discharge are comparable (Figures 14g and 14h) between the methods that rely on sedimentary structures (section 4.1) and methods based on caprock thickness and LAS curvature, which can be measured using remote sensing (sections 4.2 and 4.3). A similarity between reconstructions from sedimentology and caprock thickness was also found by Hayden et al. (2019) for nearby ridges in the Cedar Mountain Formation.

\section{Discussion}

\subsection{Sinuous Ridges in the Morrison Are Exhumed Channel Belts}

Similar to the interpretations of the sinuous ridges in the Cedar Mountain Formation by Hayden et al. (2019) and Cardenas et al. (2020), we interpret the ridges at all three of our field sites to be exhumed channel belts 

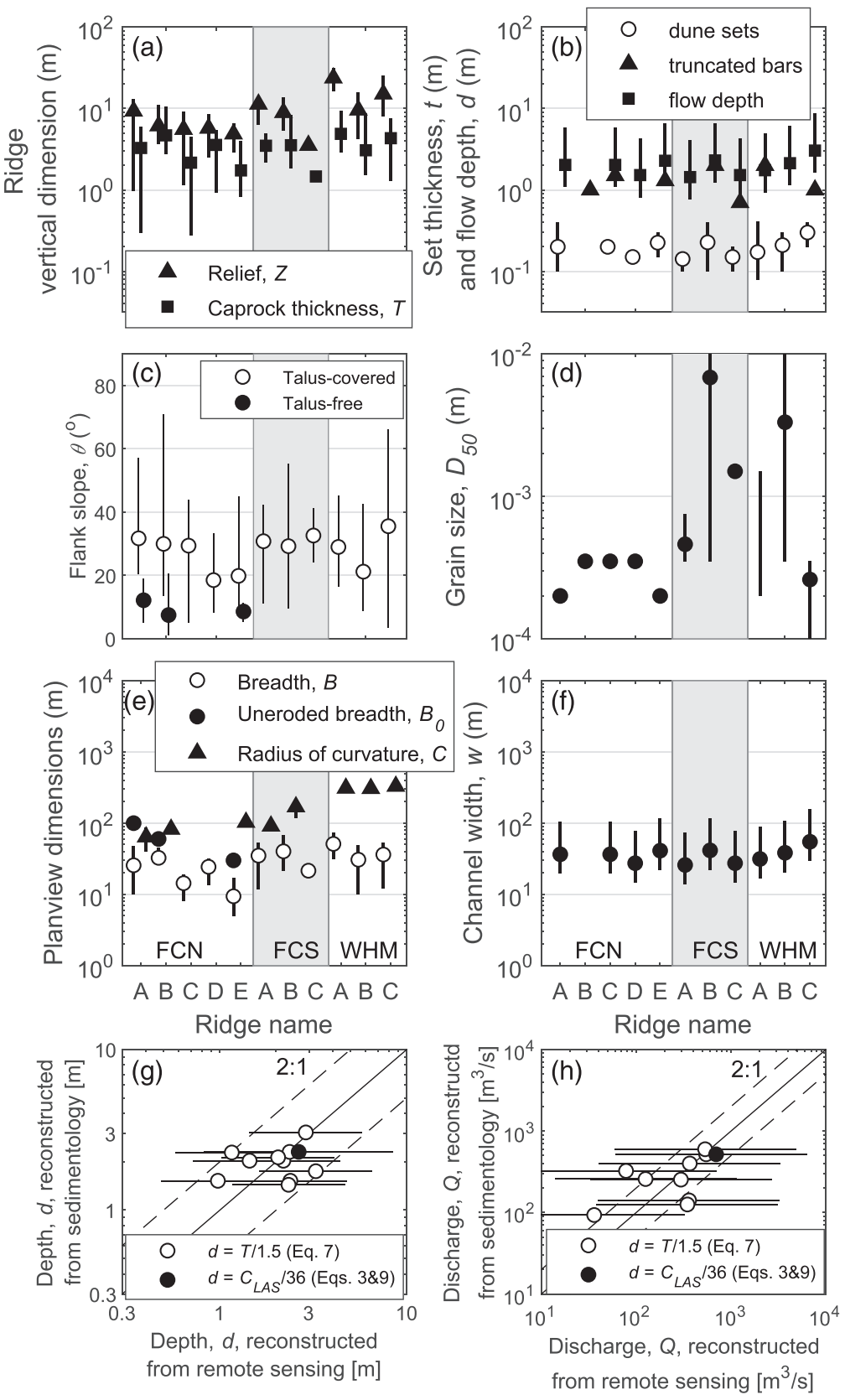

Figure 14. Ridge parameters and paleo-channel parameters and paleo-hydraulic reconstructions for the Ferron Creek North (FCN), Ferron Creek South (FCS), and Wild Horse Mesa (WHM) sites. Each point represents the median measurement for a ridge and the bar represents the 5th-95th percentile range of our observations when applicable. Ridge letters given at bottom of panels e and $\mathrm{f}$ apply to panels a-f, shaded regions divide different field areas. (a) Ridge relief and caprock thickness. (b) Thickness of cross stratification interpreted as dunes and bars (only truncated bar clinoforms were observed). These are used to reconstruct flow depth with Equations 1 or 2, which is also plotted. (c) Distribution of flank slopes on both sides of each ridge, grouped by flanks with visually very little to no talus cover $(n=12)$ and those with some or significant cover $(n=94)$. (d) Grain sizes measured in stratigraphic sections within each caprock. Dots are mean values weighted by bed thickness and bars span 5-95 percentile of measurements. Each caprock at Ferron Creek North had constant $D_{50}$. (e) Ridge breadth, uneroded breadth (measured where observed in cliff outcrops), and radius of curvature of the ridge centerline. (f) Paleo-channel width reconstruction (Equation 3). (g and h) Paleo-hydraulic reconstructions of bankfull channel depth (panel g) and bankfull water discharge (panel h) from sedimentology (section 4.1) and from ridge observations that can be made from remote sensing; white dots are using caprock thickness as a proxy for channel depth (Equation 7), and black dots use the curvature of LAS as a proxy for channel width (LAS;

Equation 9; depth is then calculated from Equation 3). Paleo-channel depth from the three reconstruction methods agree within a factor of 2 , which is the same as the estimated uncertainty in the methods (equations 1, 2, 7, and 9). 
rather than topographically inverted channel fills (i.e., inverted channels) based on the following observations. First, LAS within sandstone bodies indicate lateral channel migration across a floodplain (e.g., Ridges FCS-B, WHM-A; Figures 11 and 13a), and caprock architecture indicates channel aggradation (e.g., Ridge FCN-F; Figure 9) and/or avulsion and reoccupation, rather than filling of an abandoned channel. Caprocks are composed of amalgamated fluvial strata, including ripples, dunes, and bars, which indicates long-lived flows and reworking, and sand grain size and interpreted flow depths are consistent through each caprock section (Figure 7d, 10d, and 12d). In contrast, fluvial channel fills would be expected to be finegrained (e.g., a filled oxbow lake) and have decreasing flow depth indicators up section, as an abandoned channel pathway fills in with overbank material (Bhattacharya et al., 2016; Musial et al., 2012; Reijenstein et al., 2011). Overbank sandstone wings are interpreted as channel-levee deposits that downlap onto the floodplain (Allen et al., 1983; Friend et al., 1979; Mohrig et al., 2000) (FCN Ridges A, B, and F; Figures 8 and 9). These are the classic components of channel-belt deposits (e.g., Allen et al., 1983; Friend et al., 1979; Kjemperud et al., 2008; Mohrig et al., 2000).

Second, the uneroded sandstone bodies exposed at cliff outcrops are thicker and wider than the reconstructed paleo-channel dimensions, as expected for a channel belt. Importantly, the Morrison Formation provides important insights into the sizes of the ridge-capping sandstone bodies before they were exhumed to form ridges. Uneroded ridges have breadths up to $100 \mathrm{~m}$ (Figures 8 and 14), while paleo-channel widths were reconstructed to be less than $50 \mathrm{~m}$ (Figure 14). The thicker and wider sandstone bodies, as compared to the paleo-channel dimensions, support the interpretation that these are channel-belt deposits built through lateral channel migration, not channel fills. Further, our observations of dramatic narrowing of the sandstone bodies during ridge formation indicate that the similarity between ridge breadth and paleo-channel widths in some cases is because erosion has coincidently narrowed the channel-belt widths to sizes similar to paleo-channel width estimates in some places. However, in other locations, erosion has been negligible (e.g., next to cliffs) or has removed the ridge caprock entirely (Figure 5a), supporting the argument of Hayden et al. (2019) that ridge breadth is a highly uncertain proxy for paleo-channel width.

Third, stratigraphic superposition of multiple sandstone bodies indicates exhumation of a package of rocks formed over significant time, rather than a deflated geomorphic surface (Figures 7, 10, and 12). Field examination shows that caprocks are typically separated by floodplain facies like mudstone (Figures 8, 9, 11, and 13), indicating changes in channel location through time, with hiatuses that likely lasted thousands of years for mud accumulation and paleosol development (e.g., Leeder, 1975). Dated ash beds constrain deposition for the two members over the course of 2-6 M.y. (Figure 4). Thus, the ridges represent exhumed, stacked channel-belt deposits that accumulated by the lateral migration and aggradation of rivers over millions of years, rather than being simple inverted fills of paleo-channels.

\subsection{Ridge Modification by Scarp Retreat}

Ridges on Earth and Mars are typically observed as regional topographic highs—disconnected from outcrops where a complete section of the stratigraphy can be observed-making it difficult to constrain how much erosional modification of the ridge capping sandstone bodies occurred during ridge formation. The FCN site, where ridges emanate from cliffs, is important because it allows for an assessment of the erosion processes and geometries through observations of the preeroded sandstone body geometry, which can be used to improve our understanding of ridge formation and morphology.

Observations from FCN indicate that sandstone bodies rapidly narrow during exhumation to form a ridge (Figure 8), but the caprock thickness varies little (Figures 7, 8, 10, and 12; SI Table S1). This indicates that lateral backwasting is a major form of ridge erosion and that vertical erosion, while nonzero (e.g., there are exposed strata on ridge tops; Figures 6c, 11, and 13), is relatively minor. Data for Ridge FCN-A also shows that with distance from the cliff exposure, ridge relief increases slightly and then plateaus, caprock thickness remains roughly constant, and flank slope generally increases (Figure 8). Here we seek to explain these correlations by proposing a ridge exhumation model that incorporates scarp retreat.

We hypothesize that Ridge FCN-A was progressively exposed as the overlying rocks were removed by lateral retreat of the cliff that now abuts the ridge on its west end (Figure 7a). Thus, a space-for-time substitution can be used to understand progressive formation of the ridge. That is, near the cliff the ridge has only been recently exposed, whereas farther from the cliff the ridge has been exposed for longer and undergone more 
erosion. Thus, our observations suggest that as ridges are exhumed, their breadth decreases, ridge relief and flank slope increase, and caprock thickness remains roughly constant (Figure 8). We also observed that ridge flanks without talus often have more relaxed slopes than their talus-covered counterparts (Figure 14c) and that ridges without caprocks also lack talus on the flanks (Figure 5a). In addition, most ridges have washes at the base of their flanks that seem to be efficient at removing talus (Figures 8, 9, and 11).

We used these observations as motivation for a ridge erosion model building on previous work for scarp retreat (e.g., Glade et al., 2017; Glade \& Anderson, 2018; Ward et al., 2011). We assumed a strongly indurated caprock with thickness $(T)$ and breadth $(B)$, above a weakly indurated ridge flank with relief $(Z)$ and slope $(\theta)$ (Figure 5b). The flank erodes downward, undercutting the caprock; as the caprock is undercut, the overhang collapses and delivers the caprock material to the flank as talus.

We assumed that relief $(Z)$ increases linearly in time $(t)$ at the rate of vertical erosion into mudstone $\left(E_{m}\right)$ at the toe of the ridge flank,

$$
d Z / d t=E_{m}
$$

By geometry, breadth $(B)$ decreases as the caprock is undercut at the rate of vertical lowering of the flank projected under the ridge (Figure $5 b$ ):

$$
\frac{d B}{d t}=-\frac{2 F E_{m}}{\tan \theta}
$$

where the factor of 2 accounts for two flanks of the ridge and $F$ is the rate of vertical lowering of the ridge flank, $E_{f}$, relative to the flank toe, $E_{m}$ (i.e., $F=E_{f} / E_{m}$ ). If $F=1$, then the toe of the flank is laterally fixed by geometry, and all of the ridge relief generation by Equation 10 results in caprock undercutting. This could be the case if there is a stream at the base of the ridge that fixes the location of the flank toe. Alternatively, if $F=0$, then the ridge flank does not erode, and the ridge base increases in width to accommodate any relief generation, rather than undercutting the caprock. This could be the case if the ridge flank is armored in resistant talus.

Change in caprock thickness $(T)$ occurs at the rate of vertical caprock sandstone erosion $\left(E_{S}\right)$

$$
\frac{d T}{d t}=E_{S}
$$

By conservation of mass, talus per unit ridge length is generated by caprock undercutting at the rate $T d B /$ $d t$. Talus falls on the flank slopes, where some fraction $(f)$ stays; the remainder exits the system by rolling into the wash at the end of the slope or is eroded in situ. We track the amount of talus as a mean thickness of cover $(D)$ by averaging the total volume of talus produced $(f T d B / d t)$ over the entire length of both flanks $(2 Z / \sin \theta)$ minus the vertical erosion rate of the talus $\left(E_{t}\right)$ :

$$
\frac{d D}{d t}=f T\left(\frac{d B}{d t}\right) /\left(\frac{2 Z}{\sin \theta}\right)-E_{t}
$$

Rather than modeling any specific erosion process (e.g., gullying, soil creep; Glade et al., 2017; Glade \& Anderson, 2018; Ward et al., 2011), based on our field observations we made the assumption that flank slope is a linear function of the fraction of the flank that is covered in talus rather than mudstone (e.g., talus cover varies and flank slope increases with increasing erosion; Figures 5, 8e, and 14c). The fraction of talus cover, described as the ratio of average talus thickness, $D$, to a reference value for $100 \%$ cover, $D_{0}$, defines whether the flank slope reaches a steepness like a weak mudstone $\left(S_{m}=\tan \theta_{m}\right)$ or like a stronger sandstone $\left(S_{S}=\tan \theta_{s}\right)$

$$
\tan \theta=S_{s} /\left(\frac{S_{s}}{S_{m}}+\frac{D}{D_{0}}\left(1-\frac{S_{s}}{S_{m}}\right)\right)
$$

To solve Equations 10-14, we first nondimensionalized the equations by dividing all lengths by initial caprock thickness, $T_{0}$. Because we do not know the rates of ridge formation for our field sites, we 
eliminated time through substitution of variables and solved the equations as a function of ridge relief using Equation 10. We imposed a toppling instability for $B: T<1$, after which the caprock is completely eroded. $S_{m}$ was set from the minimum slopes observed in the field data to be $\theta_{m}=6^{\circ}$, and $S_{S}$ was set from the maximum slopes observed in the field data to be $\theta_{S}=50^{\circ}$ (Figure 14c). The ridge flanks were assumed to erode at the same rate as the flank toe (i.e., $F=1$ ) because we observed washes at the toe of most ridges that would pin the toe lateral position (e.g., Figures 7, 10, and 12) and the plain and the flanks are made of the same mudstone material (e.g., Figures 8, 9, and 11). Initial conditions for the model are $B=B_{0}$ and $T=T_{0}, \theta=\theta_{m}$, and $Z=T_{0} \tan \left(\theta_{\mathrm{m}}\right)$. Based on our field observations of negligible change in caprock thickness along a ridge (e.g., Figure 8), we also made the simplifying assumption that $E_{S}=0$. Because talus is made of the same material as the caprock, then, likewise, $E_{t}=0$. We also assumed that $D_{0}=T_{0}$ based on our observations that median talus block diameter is comparable to median caprock thickness; that is, the flank slope will be fully covered in talus when the cover is comparable to the thickness of the blocks shed from the caprock. We estimated $T_{0}$ for each ridge as the 95th percentile of the measured caprock thickness.

Even with these assumptions, the model is underdetermined because we do not know $f$ and $B_{0}$. Here we took advantage of the construct of the equations in which the flank slope in nondimensional space depends only on $f$ and $Z / T_{0}$, whereas $B$ depends additionally on $B / T_{0}$. First, we used an iterative procedure to calculate $f$, trying values between 0 and 1 , and minimized the residual sum of the square differences for the model trajectory through $\theta$ vs $Z / T_{0}$ space compared to data (Figures 15a-15c). Only Ridges FCN-A and FCN-B had enough data points to constrain $f$; we found $f=0.3,0.2$. For ridges with too few measurements to have a good fit ( $n<4$, corresponding to ridge lengths below $200 \mathrm{~m}$ ), we then applied $f=0.3$ from FCN-A to those ridges. Using the estimated $f$ for each ridge, we then found the best-fitting $B_{0}$ value by minimizing the residual sum of squares between the data and the model trajectory for $B / T_{0}$ versus $Z / T_{0}$ (Figures $15 \mathrm{~d}-15 f$ ).

As relief grows in the model, the caprock breadth narrows due to undercutting, and the flank slopes increase due to talus armoring (Figure 15). The model and data both show a slower rate of ridge narrowing with increasing relief because, by geometry, the steeper flank slope that develops due to talus armoring results in less undercutting (and therefore less ridge narrowing) per unit of flank-slope downcutting. The data also support the assumed minimum ratio of $B / T_{0}=1$ due to toppling by gravity-the model predicts a maximum ridge relief before toppling of $Z / T_{0}=2.3$ for Ridge FCN-A, which matches the maximum ridge relief achieved, while Ridge FCN-B does not reach its maximum value, which is consistent with its lack of segmentation (Figures $15 \mathrm{~d}$ and $15 \mathrm{e}$ ). The model predicts a reconstructed initial sandstone body width of $B_{0}=85 \mathrm{~m}$ $\left(B_{0} / T_{0}=18\right)$ for Ridge FCN-A, which is similar to (15\% smaller than) the measured values of $B_{0}=100 \mathrm{~m}$ at the cliff exposure (and $22 \%$ smaller than the observed $B_{0} / T_{0}=23$ ). For the other two ridges with less data due to their shorter length, we reconstruct $B_{0}=90$ and 40, which are $50 \%$ and $40 \%$ larger than the measured values; likewise, $B_{0} / T_{0}=21$ and 23 , which are $14 \%$ smaller and $35 \%$ higher than the measured values. For other ridges the calculated initial breadths $\left(B_{0}=40-160 \mathrm{~m}\right)$ are similar to those measured for nonridge forming, uneroded sandstone bodies observed elsewhere in the Morrison Formation (30-150 m; Chesley \& Leier, 2018; Owen, Jupp, et al., 2015; Stokes, 1961). This analysis suggests that the ridges analyzed have degraded breadths by 40-140 m (50-90\%). Reconstructed values of $B_{0} / T_{0}$ span 9-25, which is consistent with the smaller reported aspect ratios of channel-belt sandstone bodies from Robinson and McCabe (1997). In summary, our model provides a means to estimate original channel-belt widths from observations of ridge relief and caprock thickness and supports the idea that ridge widths can be substantially narrowed during exhumation, especially for tall ridges.

\subsection{Paleo-Hydraulics From Remote Sensing}

On Mars, detailed observations of ridge sedimentology are not possible from orbital images, and therefore, paleo-hydraulic methods that rely on ridge geometry, rather than sedimentology, are needed. It is common to use ridge width as a proxy for paleo-channel width (e.g., Burr et al., 2010; Kite et al., 2015; Williams et al., 2013). The uneroded channel-belt widths are wider than the paleo-channel widths for the Morrison ridges $\left(B_{0} / w=1.0-5.4\right)$ as expected; the ridges, however, have been subsequently narrowed $(B / w=0.1-2.4)$ by scarp retreat. While the effects of lateral migration and scarp erosion are mostly offsetting for the Morrison ridges, we are not aware of a mechanism that would make this finding 

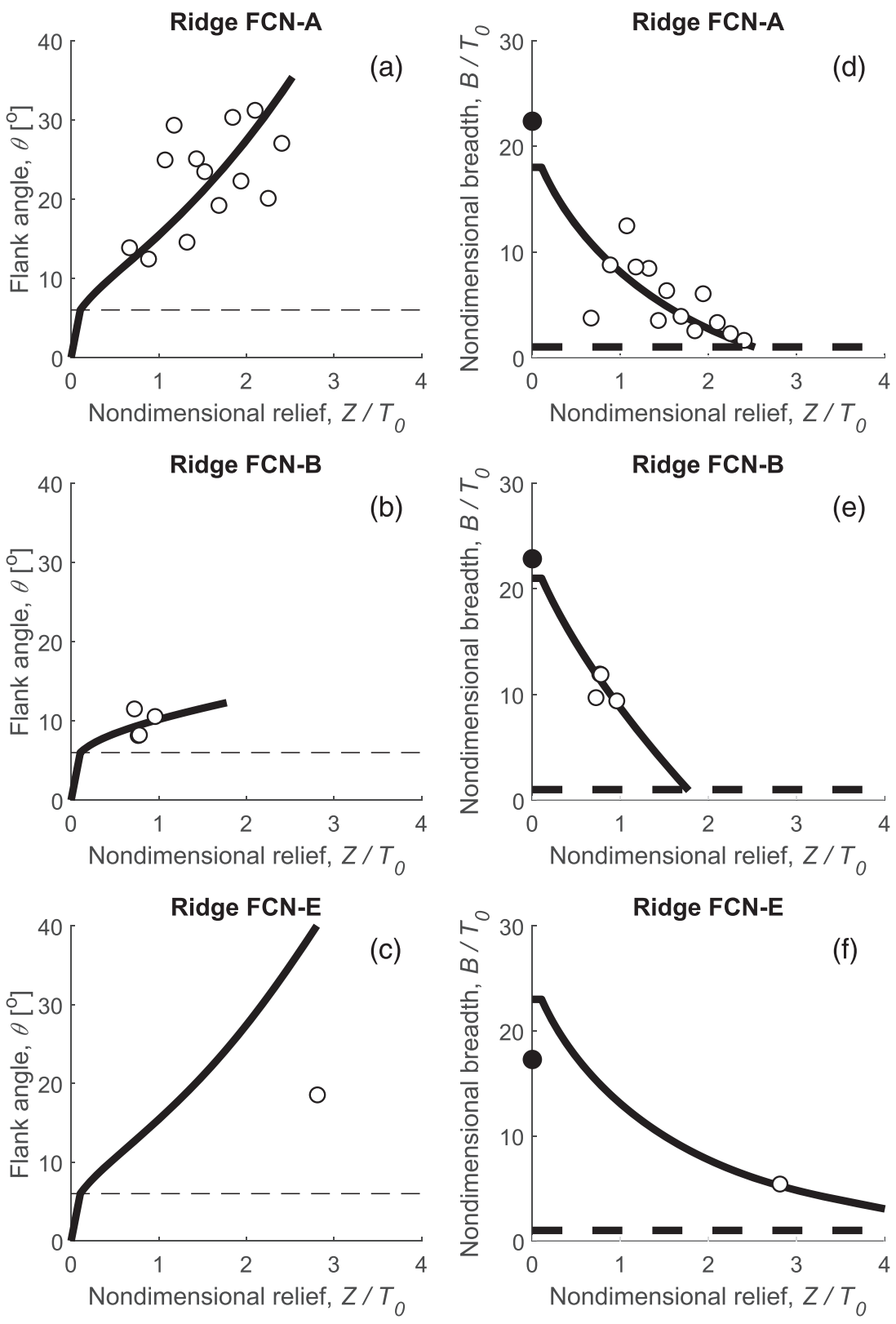

Figure 15. Ridge data and erosion model for FCN Ridges A, B, and E used to find the best-fit values for $f$, the fraction of talus produced that accumulates on the flank, and $B_{0}$, the uneroded caprock breadth. White dots are ridge data, black dots (panels d-f) are measurements of the uneroded sandstone body in cliff outcrop, and the solid lines are the model best fit (Equations 10-14). The thin dashed line in panels a-c is the minimum flank slope, $S_{m}$. The thick dashed line (panels $\mathrm{d}-\mathrm{f}$ ) is the toppling threshold of $B / T_{0}=1$. Nondimensional relief is the ridge relief $(Z)$ relative to the uneroded caprock thickness $\left(T_{0}\right)$, and the nondimensional breadth is the ridge breadth $(B)$ relative to $T_{0}$. Due to the lack of data for Ridge FCN-E, we used $f=0.3$, which is the best-fit value from FCN-A.

general. Instead, channel-belt widths are known in cases to be significantly wider than paleo-channel widths (e.g., up to a factor of 36; Hayden et al., 2019). In addition, erosion can be more or less extensive than we observed and is spatially variable along individual ridges (e.g., FCN Ridge A). Caprocks are completely absent in some cases (e.g., Figure 5a), leaving mudstone ridges that likely formed originally with a caprock, and now are in a transient state of decay. Our scarp retreat model can be used to estimate the original channel-belt width, but the conversion between channel-belt width and channel width still carries an uncertainty of several orders of magnitude (Hayden et al., 2019). 
Instead of caprock breadth, Hayden et al. (2019) advocated for use of caprock thickness as a proxy for channel depth. We find that the ratio of caprock thickness to channel depth for the Morrison ridges is $T /$ $d=0.5-1.9$, similar to the finding of Hayden et al. (2019) of $T / d=1.5$ based on the ridges of the Cedar Mountain Formation and a large compilation of nonridge forming channel-belt sandstones. Unlike caprock breadth, we expect caprock thickness to scale with channel geometry because rivers tend to be unstable and avulse, abandoning the channel-belt, after the channel aggrades by about 0.5-3 channel depths (Bryant et al., 1995; Ganti et al., 2016; Ganti, Chu, et al., 2014; Ganti, Lamb, et al., 2014; Hajek \& Wolinsky, 2012; Jerolmack \& Swenson, 2007; Mohrig et al., 2000; Slingerland \& Smith, 2004). The avulsion process, therefore, sets a relatively consistent relation between channel-belt thickness achieved just prior to avulsion and the channel depth. Furthermore, because vertical caprock erosion is small compared to lateral scarp retreat, the ridge caprock thickness can be used as a reliable proxy for the original channel-belt thickness (i.e., $T / T_{0} \approx 1$ ).

In addition to caprock thickness and breadth, Ridge FCS-B shows curvilinear features in plan view, and similar features have been interpreted as scroll bars in the Morrison Formation (e.g., Hartley et al., 2015) and on Mars (e.g., Burr et al., 2009, 2010; Jerolmack et al., 2004). Scroll bars are a series of constructional river levees deposited on the inner bank of a meandering river (Figure 3). They are perched atop the point bar and often represent only a small fraction of the sedimentary material (e.g., Mason \& Mohrig, 2019). In the Morrison Formation, we observed levee deposits in the form of climbing ripples and the sandstone wings at the margins of channel-belts (Figures 8 and 9), but these were not preserved as topographic highs during ridge formation and were not associated with the curving lines visible in plan view on the ridge tops. Instead, our observations show that the curvilinear features are outcropping beds from LAS that are topographic highs due to differential erosion on the deflated ridge top (Figure 11). That is, they are erosional features that expose point-bar cross beds that built the channel margin, rather than constructional levees from overbank deposits.

The LAS traces in plan view should be tightly correlated to channel geometry because they record the channel margin location. In contrast, we do not expect the ridge centerline curvature to track the channel curvature because the ridge is an eroded remnant of a channel belt, rather than a channel fill. For Ridge FCS-B, the LAS traces have radii of curvature from 65 to $140 \mathrm{~m}$ so are slightly smaller than the curvatures of the caprock centerline. (Individual ridge bends have radii of curvature between 120 and $500 \mathrm{~m}$ ). Using these measurements and Equation 9, we estimated a paleo-channel width of $48 \mathrm{~m}$, which is consistent with the sedimentology reconstruction (Figure 14) and the reconstruction based on caprock thickness. These paleo-hydraulic methods are further compared below in application to Mars.

\subsection{Application to Mars}

To apply the insight gained from the Morrison Formation, we illustrate the paleo-hydraulic methods and ridge erosion model with two example ridges in the Aeolis Dorsa region of Mars. Two ridges were studied because, as the ridges of the Morrison show, it is rare for individual ridges to exhibit all attributes. For the first example, we selected a broad ridge that has subparallel semicircular features on its surface that appear similar to LAS traces from the Morrison ridges (Figure 16). Many Martian ridges have LAS (e.g., Burr et al., 2009, 2010; Cardenas et al., 2018; Hughes et al., 2019); we selected this site based on its large breadth and availability of HiRISE stereo-pairs for making DEMs. We focused on a segment with a clear caprock and where the ridge is not amalgamated with other ridges (see Figure 1b). The LAS provide evidence that the ridge caprock for this example is a channel-belt deposit from a meandering river with bank attached bars that accreted laterally (i.e., point bars). The ridge also shows a semicircular trough that could represent a cutoff channel loop (e.g., an oxbow lake; Figure 16b) that was filled with mud (e.g., Musial et al., 2012; Reijenstein et al., 2011) and later exhumed, but it also could be a remnant impact crater.

We used a HiRISE stereo-DEM to measure each side of the ridge in one transect (Figure 16c), finding a caprock thickness of $7 \mathrm{~m}$ (cliffy portion of transect), relief of $3 \mathrm{~m}$, and a caprock breadth of $650 \mathrm{~m}$. In a HiRISE image we measured a radius of curvature of the ridge centerline as $C=1,200 \mathrm{~m}$, but a range of radius of curvature for the LAS that is far smaller: $C_{L A S}=48-100 \mathrm{~m}$ with a median of $55 \mathrm{~m}$ (Figure 16b). Using our scarp retreat model and the same inputs as for our sites in Utah $\left(S_{m}=0.1, S_{t}=0.8, f=0.3\right)$, we calculated a preerosion breadth of $B_{0}=690 \mathrm{~m}$ for the Martian ridge, which is similar to the measured breadth of $650 \mathrm{~m}$ due to its low relief. The depth of the putative cutoff channel loop is $2.8 \mathrm{~m}$, and its width and inner-bank 


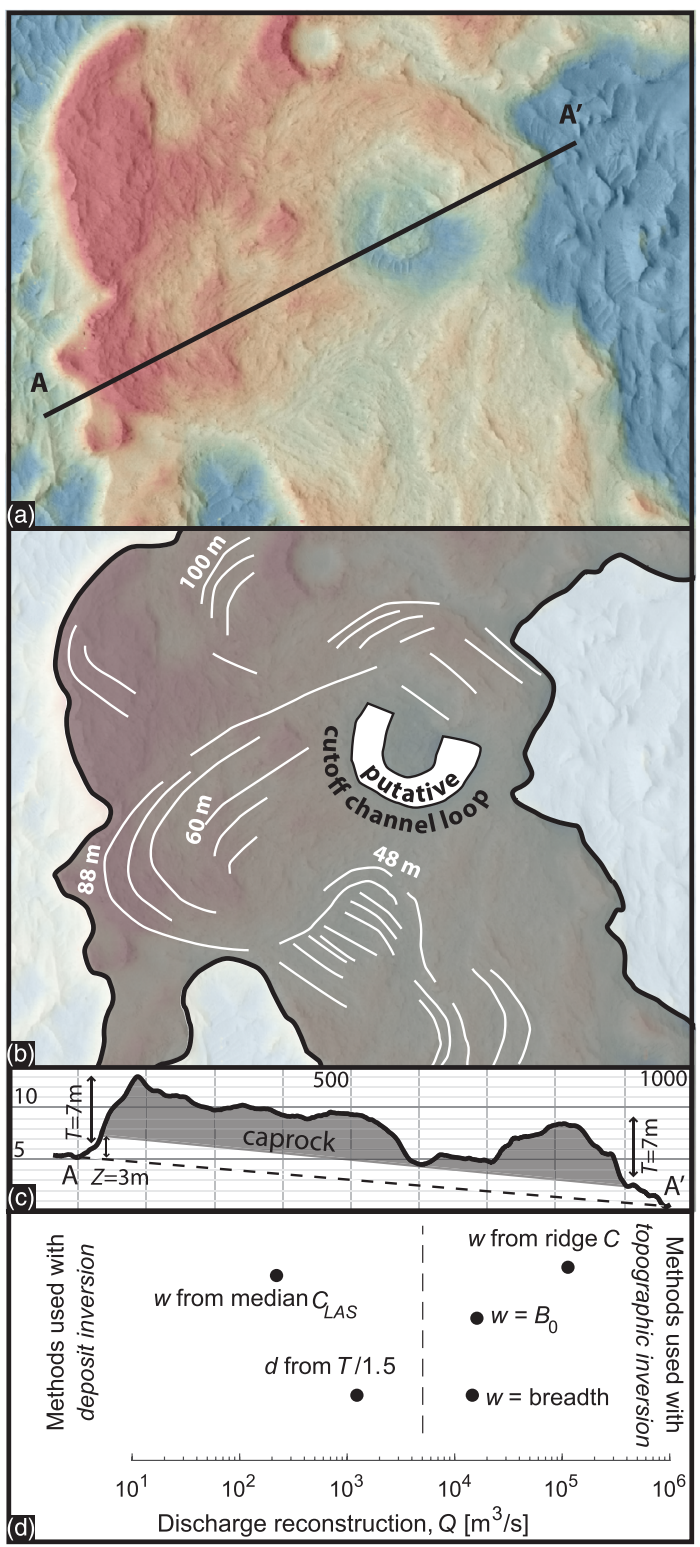

Figure 16. (a) Digital elevation model of a portion of a sinuous ridge from in Aeolis Dorsa, Mars (HiRISE image background and HiRISE stereo DEM from ESP_020805_1740 and ESP_020383_1740; 6.01 S, 153.45 E).

(b) Interpretation of panel a. This ridge has interpreted lateral accretion sets (LAS; white lines) with labeled measurements of radius of curvature and a putative cutoff channel loop. (c) Elevation transect from panel a, showing estimated caprock thickness of $T=7 \mathrm{~m}$ and estimated relief of $Z=3 \mathrm{~m}$. (d) River water discharge for the ridge, using the paleo-hydraulic methods that assume deposit inversion compared to those that assume topographic inversion. These include using radius of curvature of the LAS $\left(C_{L A S}\right)$ and ridge centerline $(C)$ as proxies for channel width $(w)$, using ridge breadth $(B)$ and modeled uneroded ridge breadth $\left(B_{0}\right)$ as proxies for channel width, and using caprock thickness $(T)$ as a proxy for channel depth $(d)$. radius of curvature are 55 and $50 \mathrm{~m}$, respectively. The similarity in the trough dimensions to their respective channel dimensions supports the interpretation of a cutoff channel loop.

Our preferred paleo-hydraulic methods, which assume exhumation of a channel belt (i.e., deposit inversion), give water discharge values that range from 310 to $1,800 \mathrm{~m}^{3} / \mathrm{s}$ for an assumed $D_{50}=3.9 \mathrm{~mm}$ (i.e., the geometric mean of the assumed end-members: 0.3 and $50 \mathrm{~mm}$ ) (Figure 16). In contrast, assuming that the breadth of the ridge or the breadth of the uneroded ridge are equal to the river width gives significantly larger discharges of 154,000 and $174,000 \mathrm{~m}^{3} / \mathrm{s}$, respectively (Figure 16). Likewise, using the ridge centerline curvature as a proxy for channel curvature yields inferred channel discharge of 51,200 $\mathrm{m}^{3} / \mathrm{s}$. These three calculations relying on an inverted-channel interpretation are consistent with each other; however, they significantly overestimate our preferred paleo-discharge values. Prior work in this region (Burr et al., 2009, 2010) avoided reconstructing discharge on features similar to this ridge ("flat" in their terminology) because they also interpreted such ridges to represent channel belts; our results therefore support their interpretation and offer a quantitative tool to calculate discharge for ridges that are exhumed channel belts.

The second example ridge from Aeolis Dorsa is one we picked because it shows narrowing along its length and so is useful to compare to our ridge erosion model (Figure 17). The first ridge was not sufficient for this example because it amalgamates with other ridges just north of the study location (Figure 1b) and is unexhumed just south of the study location. Instead, we selected a variable-width ridge from a previously studied branching ridge network (Burr et al., 2010; Hayden et al., 2019; Lefort et al., 2015) that has HiRISE stereo-pairs for creating a DEM (Figures 17a and 17b). Not all ridges have clear caprocks in topographic transects, including those in this DEM and our studied sites on Earth, so we selected this ridge mainly because the caprock could be discerned from the DEM in several places (Figure 17c). We measured caprock width and thickness, and flank slope and relief along cross-ridge transects as we did for the terrestrial ridges, differentiating the caprock from the flank by slope breaks. An estimate of uneroded caprock thickness, $T_{0}=25.8 \mathrm{~m}$, was measured as the 95 th percentile of measured caprock thicknesses along the ridge. The ridge shows an inverse correlation between caprock width and ridge relief that is concave-up like the Morrison ridges (Figure 17d), suggesting narrowing as the ridge was exhumed. Using the same parameters as we used for the Morrison ridges $\left(\theta_{m}=6^{\circ}, \theta_{s}=50^{\circ}, E_{s}=E_{t}=0, f=0.3, F=1\right)$, we found the model yielded predictions of ridge narrowing greater than observed for a given change in relief (Figure 17d). By changing $F$ to 0.2, we found a better fit between the model and data, and predicted that that $B_{0}=130 \mathrm{~m}$. This lower value of $F$ implies that the vertical erosion rate on the ridge flank $\left(E_{f}\right)$ is smaller than the vertical erosion rate at the toe of the ridge $\left(E_{m}\right)$ (Figure $\left.5 b\right)$. In other words, as the ridge increased in relief due to differential erosion between the ridge toe and the ridge caprock, only a fraction (20\%) of that differential erosion led to caprock undercutting; the remainder of the relief was accommodated by lengthening of the ridge flank and widening of the ridge base.

There are several possible mechanisms that might explain our finding of $F<1$ for the Martian ridge. First, a talus armor could slow the erosion on the talus flank relative to the toe of the ridge; however, we found a good model fit for terrestrial ridges of $F=1$ (Figure 14) despite abundant talus (Figure 1d). Moreover, at 


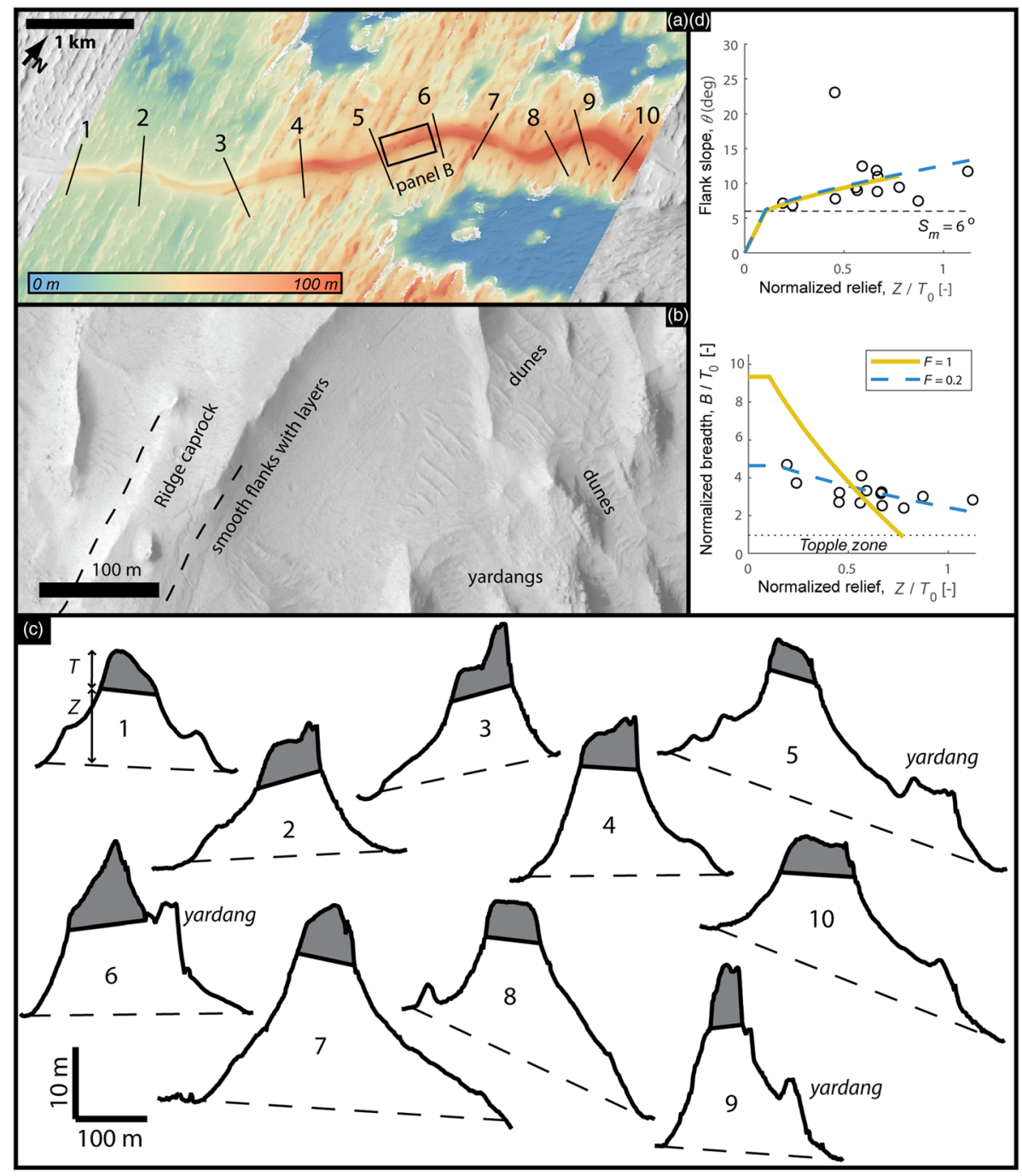

Figure 17. Ridge in Aeolis Dorsa, Mars (6.24 S, 151.43 E). (a) We measured 10 transects (black lines) along the ridge in a HiRISE stereo-pair DEM (PSS_002279_1735 and PSP_002002_1735). (b) Zoomed-in view from panel (a) showing ridge caprock, flank slopes with layering, and eolian dunes and yardangs. (c) Topographic profiles from HiRISE DEM shown at 10 times vertical exaggeration, with locations given in panel (a). Gray shaded area is the interpreted caprock. Dashed lines connect the base of each ridge flank, as defined by a change in slope to the neighboring terrain. Some ridge flanks show yardangs in the topographic profile. d. Data from the ridges (circles) and our model (colored lines) with $F=1$ (as found for terrestrial ridges) and the best-fit value $F=0.2$, showing ridge flank slope angle $(\theta)$ as a function of nondimensional relief $\left(Z / T_{0}\right)$ and nondimensional breadth $\left(B / T_{0}\right)$ as a function of nondimensional relief.

the resolution of HiRISE ( $<1 \mathrm{~m}$ per pixel), we did not observe talus on the flanks in this example (although talus is observed elsewhere in the same HiRISE image; Figure 1c), and we expect it to be visible if talus size scales with $T_{0}$. Instead, the ridge flank shows horizontal lineations, which we interpret to be exposed beds of the underlying strata (Figure 17b). A second possible mechanism is that eolian abrasion might be more effective on the plains surrounding the ridge as compared to on the ridge flanks. For example, saltating grains that are responsible for eolian erosion (e.g., Bagnold, 1941) might be deflected away from the flanks toward the plains. A third possible mechanism is that the ridge flank material is more resistant to erosion than the plains beyond the ridge toe. This mechanism could be possible at Aeolis Dorsa; while the ridge flank is relatively smooth and has exposed bedding, the plains appear to be composed of a different material that drapes the ridge flank and produces yardangs (Figure 17b). This observation is different than the Morrison ridges where the ridge flanks and toes are composed of the same floodplain facies that erodes similarly and where modern washes define ridge toes and likely pin them in place. 
Unlike the example ridge in Figure 16, this ridge (Figure 17) would be classified as a "thin" ridge and an inverted channel under the criteria of Burr et al. (2009, 2010). Therefore, the ridge in Figure 17 is one in which paleo-discharge might be calculated from ridge width and wavelength directly as if the ridge were a mold of the channel dimensions. In contrast, we interpret this ridge, similar to the Morrison ridges, as a channel belt due to layering in the flanks that suggest exposed bedding planes (Figure 17b) and ridge stacking observed elsewhere in the same network (Hayden et al., 2019). In this case, the values for flood discharge using measurements of width as a proxy for channel width $\left(\sim 150 \mathrm{~m}^{3} / \mathrm{s}\right.$; Burr et al., 2010$)$ are significantly smaller than those based on using caprock thickness as a proxy for channel depth (mean thickness $13.0 \mathrm{~m}$ yields $Q=4,500 \mathrm{~m}^{3} / \mathrm{s}$ ). However, because channel belts have width and thickness that relate independently to paleochannel geometry (e.g., Jerolmack \& Mohrig, 2007), in other cases, calculations based on caprock width can be similar to or greatly exceed calculations based on caprock thickness (e.g., Figure 16).

\subsection{Implications for Mars}

The ridge-forming processes observed for the Morrison ridges-channel-belt construction through river migration and aggradation, then later exhumation and scarp erosion-are also observed on Mars. There are numerous examples of exposed LAS on fluvial ridges on Mars that have been interpreted to represent channel belts of meandering rivers (Cardenas et al., 2018; Kite et al., 2015; Malin \& Edgett, 2003), layered sediments that indicate vertical aggradation (DiBiase et al., 2013; Figure 17b), and talus-strewn flank slopes indicating caprock erosion (e.g., Figure 1c). In these cases, due to the combined effects of deposit amalgamation and scarp-retreat erosion, caprock breadth is unlikely to directly represent paleo-channel width, while caprock thickness can be related to paleo-channel depth by Equation 7.

One difference between ridges on Earth and Mars is that the dominant type of erosion has likely been eolian on Mars (e.g., Zimbelman \& Griffin, 2010), whereas rainfall and runoff erosion is important for the Morrison Formation. This potentially explains some differences in ridge morphology, such as the existence of ridges extending for hundreds of kilometers on Mars (Burr et al., 2009; Williams et al., 2013), whereas terrestrial ridges are much shorter; terrestrial ridges are often segmented by fluvial washes (e.g., Figures 7, 10, and 12; Cardenas et al., 2020; Hayden al., 2019; Williams et al., 2009). However, scarp-retreat that causes ridge narrowing likely also occurs on Mars. For example, talus mantling the slopes of some ridges and variable caprock widths suggests erosion by scarp retreat (Figure 1c). The lower value of $F$ (flank slope erosion relative to flank toe erosion) we observed for one ridge in Aeolis Dorsa, if prevalent across Mars, indicates that ridges can grow taller and wider and have better caprock preservation than their terrestrial counterparts for a given set of channel-belt dimensions $\left(B_{0}, T_{0}\right)$. Therefore, taller and wider ridges on Mars (e.g., Kite et al., 2019) might not necessarily indicate larger Martian river channels, or even larger Martian channel belts; wider ridges, instead, could simply reflect systematic differences in erosional processes between Mars and Earth. Smaller $F$ also is consistent with longer continuous lengths of ridges on Mars (e.g., Burr et al., 2009; Williams et al., 2013) because higher relief would be needed in order for ridges to reach the toppling threshold (Figure 17d). However, additional work is needed to determine if this explanation for long ridges is applicable across Mars. The toppling threshold is further useful on Mars because where caprocks are heavily degraded and discontinuous, the narrowest caprock widths may be an indicator of caprock thickness (i.e., $B \sim T$ at the threshold of toppling), and caprock thickness, in turn, scales with channel depth (Equation 7).

A useful diagnostic indicator from orbital images that a ridge is an exhumed channel-belt deposit is the occurrence of LAS, and LAS also appear to be robust paleo-hydraulic indicators. Though several instances of LAS on Mars have been studied for paleo-hydraulic reconstructions (e.g., Eberswalde and Jezero Craters; e.g., Irwin et al., 2015; Goudge et al., 2018), most occurrences of LAS likely will not be observable from orbit; this requires particular circumstances so that differential erosion of LAS beds produces a significant texture on the ridge top at a scale that is coarser than the image resolution. Thus, the absence of such features does not imply the absence of a channel-belt deposit. For example, we made field observations of laterally aggrading bars at WHM (Figure 13a) and FCN but did not observe LAS in the $10 \mathrm{~cm} / \mathrm{px}$ quadcopter photographs. In the ridges in the nearby Cedar Mountain Formation, Harris (1980) also identified 12 point bars (also documented by Cardenas et al., 2020; Hayden al., 2019; Williams et al., 2009), but the LAS from these deposits are not evident in $\sim 20 \mathrm{~cm} / \mathrm{px}$ images in Google Earth.

Vertical stacking and crosscutting of ridge-capping sandstone bodies is another indicator for exhumation of a sequence of fluvial strata, rather than a topographically inverted geomorphic surface (DiBiase et al., 2013; 
Hayden et al., 2019; Kite et al., 2013). Interpreting channel belts from this method likely has a lower rate of false negatives than searching for LAS, but stratigraphic offsets can be only decimeters to meters in cases (e.g., Figures 7d, 10d, and 12d), which also can be difficult to detect on Mars.

\section{Conclusions}

Ridges in the Morrison Formation, Utah, stand 4-24 m above the surrounding plains and have caprocks 1.4$4.9 \mathrm{~m}$ thick and 10-50 $\mathrm{m}$ in breadth. The ridges are composed of a caprock sandstone that overlies mudstone. The sandstone bodies contain dune trough cross strata and bar-scale LAS that indicate deposits from aggrading and laterally migrating rivers and, therefore, are channel-belt deposits, rather than channel fills. Ridge caprocks occur at distinct stratigraphic levels, and reflect exhumation of a thick sequence of sedimentary strata formed over millions of years, rather than topographically inverted channels. Comparison to outcrop exposures showed that channel-belt sandstones have narrowed by 50-90\% during exhumation to form a ridge, removing neighboring floodplain mudstones, overbank sandstones and levees, and major sections of the channel belt. A new scarp-retreat model describes ridge relief growth due to differential erosion between the mudstone flanks and capping sandstone, which causes ridge narrowing by flank erosion and flank steepening in response to talus accumulation. Using the model, the original uneroded channel-belt dimensions can be estimated from measurements of ridge relief and caprock thickness.

We estimated the paleo-channel depth and discharge based on well-tested relations that rely on observations of grain size and dune and bar cross strata set thickness and used these estimates to evaluate paleo-hydraulic reconstruction methods that can be used on Mars because they rely only on remote sensing observations. The most reliable methods were to use caprock thickness as a proxy for river depth $(T / d=1.5)$ or to use the radius of curvature of LAS as a proxy for river width $\left(w / C_{L A S}=0.5\right)$. LAS curvature can be measured from curvilinear features on ridge tops that result from the intersection of LAS beds, formed during meandering, with the deflating land surface. These features on Mars are often interpreted as constructional scroll bars or levees but are more consistent with eroded tops of LAS. Ridge widths can be larger or smaller than paleo-channel widths depending on the relative amounts of channel lateral migration during channel-belt formation and scarp retreat during ridge formation. In the Morrison Formation, these two processes largely offset to give ridge widths similar to the estimated paleo-channel widths, but we do not expect this result to be general.

The ridge-forming processes observed in the Morrison Formation are also observed on Mars, including ridges at multiple stratigraphic levels and LAS, which supports formation by exhumation of channel belts, rather than topographic inversion of channels. An example ridge in Aeolis Dorsa, Mars, contains LAS traces suggesting it is an exhumed channel belt. Using caprock thickness and radius of curvature of LAS to reconstruct river discharge yields similar results. In contrast, using ridge width or ridge centerline curvature, under the inverted channel hypothesis, results in discharges 30-500 times larger. Another example ridge has caprock and flank dimensions that match predictions from the scarp-retreat erosion model—including decreasing ridge breadth with increasing ridge relief-but with lower relative erodibility of the ridge flank than the Morrison ridges. Thus, the generally wider, longer, and more continuous ridge segments on Mars, as compared to Earth, might imply differences in erosion processes rather than larger river channels or channel belts on Mars.

Channel belt exhumation implies that ridges represent fluvial strata deposited over geologic time rather than a preserved landscape at a snapshot in time. Thus, the potential preservation of fluvial strata in ridges makes them optimal targets for exploration with upcoming rover missions.

\section{Conflict of Interest}

The authors have no real or perceived financial conflicts of interest.

\section{Data Availability Statement}

Supporting information includes Table S1 (raw ridge measurements), Table S2 (raw sedimentology measurements), and Table S3 (summary measurements). The lidar DEM of the Ferron Creek field sites is on the NCALM website (http://calm.geo.berkeley.edu/ncalm/dtc.html), and the HiRISE stereo DEMs are 
accessible on the Geoscience node of the NASA Planetary Data System (https://pds-geosciences.wustl.edu/ dataserv/default.htm).

\section{Acknowledgments}

The authors wish to thank the members of Caltech's fall 2015 advanced field course (Joe Biasi, Austin Chadwick, Florian Hoffman, Ellen Leask, Luca Malatesta, and Marshall Trautman) for field assistance. Thanks to Jay Dickson for the HiRISE stereo DEM analyzed in Figure 17 and to NSF National Center for Airborne Laser Mapping for the lidar for the Ferron Creek sites (seed grant Project ID 2016-06). Thanks also to T. A. Goudge and R. M. E. Williams for their formal reviews that helped us improve the manuscript. This work was supported by NASA (grant

NNX16AQ81G to M. P. L. and graduate fellowship support 80NSSC17K0492 to A. T. H.).

\section{References}

Allen, J. R. (1963). The classification of cross-stratified units. With notes on their origin. Sedimentology, 2(2), 93-114. https://doi.org/ 10.1111/j.1365-3091.1963.tb01204.x

Allen, P., Cabrera, L., Colombo, F., \& Matter, A. (1983). Variations in fluvial style on the Eocene-Oligocene alluvial fan of the Scala Dei

Bagnold, R. (1941). The physics of blown sand and desert dunes. New York, NY: William Morrow \& Company.

Balme, M. R., Gupta, S., Davis, J. M., Fawdon, P., Grindrod, P. M., Bridges, J. C., et al. (2020). Aram Dorsum: An extensive mid-Noachian age fluvial depositional system in Arabia Terra, Mars. Journal of Geophysical Research: Planets, 125, e2019JE006244. https://doi.org/ 10.1029/2019JE006244

Bhattacharya, J. P., Copeland, P., Lawton, T. F., \& Holbrook, J. (2016). Estimation of source area, river paleo-discharge, paleoslope, and sediment budgets of linked deep-time depositional systems and implications for hydrocarbon potential. Earth-Science Reviews, 153, 77-110. https://doi.org/10.1016/j.earscirev.2015.10.013

Blum, M., Martin, J., Milliken, K., \& Garvin, M. (2013). Paleovalley systems: Insights from Quaternary analogs and experiments. EarthScience Reviews, 116, 128-169. https://doi.org/10.1016/j.earscirev.2012.09.003

Bradley, R. W., \& Venditti, J. G. (2017). Reevaluating dune scaling relations. Earth-Science Reviews, 165, 356-376. https://doi.org/10.1016/j. earscirev.2016.11.004

Bridge, J. (2003). Rivers and floodplains. Malden, MA: Blackwell Publishing.

Bryant, M., Falk, P., \& Paola, C. (1995). Experimental study of avulsion frequency and rate of deposition. Geology, 23(4), 365. https://doi. Group, SE Ebro Basin, Spain. Journal of the Geological Society, 140(1), 133-146. https://doi.org/10.1144/gsjgs.140.1.0133 org/10.1130/0091-7613(1995)023<0365:esoafa $>2.3 . c 0 ; 2$

Burr, D. M., Enga, M.-T., Williams, R. M. E., Zimbelman, J. R., Howard, A. D., \& Brennand, T. A. (2009). Pervasive aqueous paleoflow features in the Aeolis/Zephyria Plana region, Mars. Icarus, 200(1), 52-76. https://doi.org/10.1016/j.icarus.2008.10.014

Burr, D. M., Williams, R. M. E., Wendell, K. D., Chojnacki, M., \& Emery, J. P. (2010). Inverted fluvial features in the Aeolis/Zephyria Plana region, Mars: Formation mechanism and initial paleodischarge estimates. Journal of Geophysical Research, 115, E07011. https://doi.org/ 10.1029/2009JE003496

Cardenas, B. T., Mohrig, D., \& Goudge, T. A. (2018). Fluvial stratigraphy of valley fills at Aeolis Dorsa, Mars: Evidence for base-level fluctuations controlled by a downstream water body. GSA Bulletin, 130, 484-498. https://doi.org/10.1130/b31567.1

Cardenas, B. T., Mohrig, D., Goudge, T. A., Hughes, C. M., Levy, J. S., Swanson, T., et al. (2020). The anatomy of exhumed river-channel belts: Bedform to belt-scale river kinematics of the Ruby Ranch Member, Cretaceous Cedar Mountain Formation, Utah, USA. Sedimentology, sed.12765. https://doi.org/10.1111/sed.12765

Chesley, J. T., \& Leier, A. L. (2018). Sandstone-body variability in the medial-distal part of an ancient distributive fluvial system, Salt Wash Member of the Morrison Formation, Utah, USA. Journal of Sedimentary Research, 88, 568-582. https://doi.org/10.2110/ jsr.2018.32

Christiansen, E. H., Kowallis, B. J., Dorais, M. J., Hart, G. L., Mills, C. N., Pickard, M., \& Parks, E. (2015). The record of volcanism in the Brushy Basin Member of the Morrison Formation: Implications for the Late Jurassic of western North America. In Late Jurassic Margin of Laurasia-A Record of Faulting Accommodating Plate Rotation, GSA Special Papers (Vol. 513, pp. SPE513-SPE511). Boulder, CO: Geological Society of America. https://doi.org/10.1130/2015.2513(11)

Clarke, J. D. A., \& Stoker, C. R. (2011). Concretions in exhumed and inverted channels near Hanksville Utah: Implications for Mars. International Journal of Astrobiology, 10(3), 161-175. https://doi.org/10.1017/s1473550411000048

Davis, J. M., Balme, M., Grindrod, P. M., Williams, R. M. E., \& Gupta, S. (2016). Extensive Noachian fluvial systems in Arabia Terra: Implications for early Martian climate. Geology, 44, 847-850. https://doi.org/10.1130/g38247.1

Davis, J. M., Gupta, S., Balme, M., Grindrod, P. M., Fawdon, P., Dickeson, Z. I., \& Williams, R. M. E. (2019). A diverse array of fluvial depositional systems in Arabia Terra: Evidence for mid-Noachian to Early Hesperian rivers on Mars. Journal of Geophysical Research: Planets, 124, 1913-1934. https://doi.org/10.1029/2019JE005976

Demko, T. M., Currie, B. S., \& Nicoll, K. A. (2004). Regional paleoclimatic and stratigraphic implications of paleosols and fluvial/overbank architecture in the Morrison Formation (Upper Jurassic), Western Interior, USA. Sedimentary Geology, 167, 115-135. https://doi.org/ 10.1016/j.sedgeo.2004.01.003

Derr, M. E. (1974). Sedimentary structure and depositional environment of paleo-channels in the Jurassic Morrison Formation near Green River, Utah. Provo, UT: Department of Geology, Brigham Young University.

DiBiase, R. A., Limaye, A. B., Scheingross, J. S., Fischer, W. W., \& Lamb, M. P. (2013). Deltaic deposits at Aeolis Dorsa: Sedimentary evidence for a standing body of water on the northern plains of Mars. Journal of Geophysical Research: Planets, 118, 1285-1302. https://doi. org/10.1002/jgre.20100

Doelling, H. H., Kuehne, P. A., Willis, G. C., \& Ehler, J. B. (2015). Geologic map of the San Rafael Desert 30' $\times 60^{\prime}$ Quadrangle, Emery and Grand Counties, Utah. (M-267dm). UT: Utah Geological Survey.

Dury, G. H. (1976). Discharge prediction, present and former, from channel dimensions. Journal of Hydrology, 30(3), 219-245. https://doi. org/10.1016/0022-1694(76)90102-5

Eaton, B. (2013). Hydraulic geometry: Empirical investigations and theoretical approaches. Treatise on geomorphology, fluvial geomorphology, 9, 313-329.

Einstein, H. A. (1950). The bed-load function for sediment transportation in open channel flows (United States Department of Agriculture Technical Report 1026).

Engelund, F., \& Hansen, E. (1967). A monograph on sediment transport in alluvial streams. Copenhagen: Technical University of Denmark.

Ferguson, R. J., \& Brierley, G. J. (1999). Levee morphology and sedimentology along the lower Tuross River, south-eastern Australia. Sedimentology, 46(4), 627-648. https://doi.org/10.1046/j.1365-3091.1999.00235.x

Friend, P. F., Slater, M. J., \& Williams, R. C. (1979). Vertical and lateral building of river sandstone bodies, Ebro Basin, Spain. Journal of the Geological Society, 136(1), 39-46. https://doi.org/10.1144/gsigs.136.1.0039

Galli, K. G. (2014). Fluvial architecture element analysis of the Brushy basin Member, Morrison Formation, western Colorado, USA. Volumina Jurassica, 12, 69-106. https://doi.org/10.5604/17313708.1130130 
Ganti, V., Chadwick, A. J., Hassenruck-Gudipati, H. J., \& Lamb, M. P. (2016). Avulsion cycles and their stratigraphic signature on an experimental backwater-controlled delta. Journal of Geophysical Research: Earth Surface, 121, 1651-1675. https://doi.org/10.1002/ 2016JF003915

Ganti, V., Chu, Z., Lamb, M. P., Nittrouer, J. A., \& Parker, G. (2014). Testing morphodynamic controls on the location and frequency of river avulsions on fans versus deltas: Huanghe (Yellow River), China. Geophysical Research Letters, 41, 7882-7890. https://doi.org/ 10.1002/2014GL061918

Ganti, V., Lamb, M. P., \& McElroy, B. (2014). Quantitative bounds on morphodynamics and implications for reading the sedimentary record. Nature Communications, 5(1), 3298. https://doi.org/10.1038/ncomms4298

Gibling, M. R. (2006). Width and thickness of fluvial channel bodies and valley fills in the geological record: A literature compilation and classification. Journal of Sedimentary Research, 76(5), 731-770. https://doi.org/10.2110/jsr.2006.060

Glade, R. C., \& Anderson, R. S. (2018). Quasi-steady evolution of hillslopes in layered landscapes: An analytic approach. Journal of Geophysical Research: Earth Surface, 123, 26-45. https://doi.org/10.1002/2017JF004466

Glade, R. C., Anderson, R. S., \& Tucker, G. E. (2017). Block-controlled hillslope form and persistence of topography in rocky landscapes. Geology, 45(4), 311-314. https://doi.org/10.1130/g38665.1

Goudge, T. A., Mohrig, D., Cardenas, B. T., Hughes, C. M., \& Fassett, C. I. (2018). Stratigraphy and paleohydrology of delta channel deposits, Jezero crater, Mars. Icarus, 301, 58-75. https://doi.org/10.1016/j.icarus.2017.09.034

Hajek, E. A., \& Heller, P. L. (2012). Flow-depth scaling in alluvial architecture and nonmarine sequence stratigraphy: Example from the Castlegate Sandstone, Central Utah, U.S.A. Journal of Sedimentary Research, 82(2), 121-130. https://doi.org/10.2110/jsr.2012.8

Hajek, E. A., \& Wolinsky, M. A. (2012). Simplified process modeling of river avulsion and alluvial architecture: Connecting models and field data. Sedimentary Geology, 257-260, 1-30. https://doi.org/10.1016/j.sedgeo.2011.09.005

Harris, D. R. (1980). Exhumed paleo-channels in the Lower Cretaceous Cedar Mountain Formation near Green River, Utah (Vol. 27, pp. 51-66). Provo, UT: Brigham Young University.

Hartley, A. J., Owen, A., Swan, A., Weissmann, G. S., Holzweber, B. I., Howell, J., et al. (2015). Recognition and importance of amalgamated sandy meander belts in the continental rock record. Geology, 43, 679-682. https://doi.org/10.1130/g36743.1

Hasiotis, S. T. (2004). Reconnaissance of Upper Jurassic Morrison Formation ichnofossils, Rocky Mountain Region, USA: Paleoenvironmental, stratigraphic, and paleoclimatic significance of terrestrial and freshwater ichnocoenoses. Sedimentary Geology, 167(3-4), 177-268. https://doi.org/10.1016/j.sedgeo.2004.01.006

Hayden, A. T., Lamb, M. P., Fischer, W. W., Ewing, R. C., McElroy, B., \& Williams, R. M. E. (2019). Formation of sinuous ridges by inversion of river-channel belts in Utah, USA, with implications for Mars. Icarus, 332, 92-110. https://doi.org/10.1016/j. icarus.2019.04.019

Heller, P. L., Ratigan, D., Trampush, S., Noda, A., McElroy, B., Drever, J., \& Huzurbazar, S. (2015). Origins of bimodal stratigraphy in fluvial deposits: An example from the Morrison Formation (Upper Jurassic), Western USA. Journal of Sedimentary Research, 85, $1466-1477$. https://doi.org/10.2110/jsr.2015.93

Hickin, E. J. (1978). Mean flow structure in meanders of the Squamish River, British Columbia. Canadian Journal of Earth Sciences, 15(11), 1833-1849. https://doi.org/10.1139/e78-191

Hughes, C. M., Cardenas, B. T., Goudge, T. A., \& Mohrig, D. (2019). Deltaic deposits indicative of a paleo-coastline at Aeolis Dorsa, Mars. Icarus, 317, 442-453. https://doi.org/10.1016/j.icarus.2018.08.009

Irwin, R. P., Lewis, K. W., Howard, A. D., \& Grant, J. A. (2015). Paleohydrology of Eberswalde crater, Mars. Geomorphology, 240, 83-101. https://doi.org/10.1016/j.geomorph.2014.10.012

Jacobsen, R. E., \& Burr, D. M. (2018). Errors in Martian paleodischarges skew interpretations of hydrologic history: Case study of the Aeolis Dorsa, Mars, with insights from the Quinn River, NV. Icarus, 302, 407-417. https://doi.org/10.1016/j.icarus.2017.11.014

Jerolmack, D. J., \& Mohrig, D. (2007). Conditions for branching in depositional rivers. Geology, 35(5), 463-466. https://doi.org/10.1130/ G23308A.1

Jerolmack, D. J., Mohrig, D., Zuber, M. T., \& Byrne, S. (2004). A minimum time for the formation of Holden Northeast fan, Mars. Geophysical Research Letters, 31, 1329. https://doi.org/10.1029/2004GL021326

Jerolmack, D. J., \& Swenson, J. B. (2007). Scaling relationships and evolution of distributary networks on wave-influenced deltas. Geophysical Research Letters, 34, L23402. https://doi.org/10.1029/2007gl031823

Kirkland, J. I., Cifelli, R. L., Britt, B. B., Burge, D. L., DeCourten, F. L., Eaton, J. G., \& Parrish, J. M. (1999). Distribution of vertebrate faunas in the Cedar Mountain Formation, east-central Utah. In Vertebrate paleontology in Utah (Vol. 1, pp. 201-217). Utah Geological Survey Miscellaneous Publication.

Kite, E. S., Howard, A. D., Lucas, A., \& Lewis, K. W. (2015). Resolving the era of river-forming climates on Mars using stratigraphic logs of river-deposit dimensions. Earth and Planetary Science Letters, 420, 55-65. https://doi.org/10.1016/j.epsl.2015.03.019

Kite, E. S., Lucas, A., \& Fassett, C. I. (2013). Pacing early Mars river activity: Embedded craters in the Aeolis Dorsa region imply river activity spanned $\gtrsim(1-20)$ Myr. Icarus, 225, 850-855. https://doi.org/10.1016/j.icarus.2013.03.029

Kite, E. S., Mayer, D. P., Wilson, S. A., Davis, J. M., Lucas, A. S., \& de Quay, G. S. (2019). Persistence of intense, climate-driven runoff late in Mars history. Science Advances, 5, eaav7710. https://doi.org/10.1126/sciadv.aav7710

Kjemperud, A. V., Schomacker, E. R., \& Cross, T. A. (2008). Architecture and stratigraphy of alluvial deposits, Morrison formation (Upper Jurassic), Utah. AAPG Bulletin, 92(8), 1055-1076. https://doi.org/10.1306/03250807115

Leclair, S. F., \& Bridge, J. S. (2001). Quantitative interpretation of sedimentary structures formed by river dunes. Journal of Sedimentary Research, 71(5), 713-716. https://doi.org/10.1306/2DC40962-0E47-11D7-8643000102C1865D

Leeder, M. (1975). Pedogenic carbonates and flood sediment accretion rates: A quantitative model for alluvial arid-zone lithofacies. Geological Magazine, 112(3), 257-270. https://doi.org/10.1017/S0016756800047014

Lefort, A., Burr, D. M., Beyer, R. A., \& Howard, A. D. (2012). Inverted fluvial features in the Aeolis-Zephyria Plana, western Medusae Fossae Formation, Mars: Evidence for post-formation modification. Journal of Geophysical Research, 117, E03007. https://doi.org/ 10.1029/2011JE004008

Lefort, A., Burr, D. M., Nimmo, F., \& Jacobsen, R. E. (2015). Channel slope reversal near the Martian dichotomy boundary: Testing tectonic hypotheses. Geomorphology, 240, 121-136. https://doi.org/10.1016/j.geomorph.2014.09.028

Leopold, L. B., Wolman, M. G., \& Miller, J. P. (1964). Fluvial processes in geomorphology. Courier Corporation.

Mackey, S. D., \& Bridge, J. S. (1995). Three-dimensional model of alluvial stratigraphy: Theory and application. Journal of Sedimentary Research, 65(1b), 7-31. https://doi.org/10.1306/D42681D5-2B26-11D7-8648000102C1865D

Malin, M. C., \& Edgett, K. S. (2003). Evidence for persistent flow and aqueous sedimentation on early Mars. Science, 302(5652), 1931-1934. https://doi.org/10.1126/science.1090544 
Mason, J., \& Mohrig, D. (2019). Scroll bars are inner bank levees along meandering river bends. Earth Surface Processes and Landforms, 44(13), 2649-2659. https://doi.org/10.1002/esp.4690

McLaurin, B. T., \& Steel, R. J. (2007). Architecture and origin of an amalgamated fluvial sheet sand, lower Castlegate Formation, Book Cliffs, Utah. Sedimentary Geology, 197(3-4), 291-311. https://doi.org/10.1016/j.sedgeo.2006.10.005

Mohrig, D., Heller, P. L., Paola, C., \& Lyons, W. J. (2000). Interpreting avulsion process from ancient alluvial sequences: GuadalopeMatarranya system (northern Spain) and Wasatch Formation (western Colorado). Geological Society of America Bulletin, 112(12), 1787-1803. https://doi.org/10.1130/0016-7606(2000)112<1787:IAPFAA >2.0.CO;2

Moore, J. M., Howard, A. D., Dietrich, W. E., \& Schenk, P. M. (2003). Martian layered fluvial deposits: Implications for Noachian climate scenarios. Geophysical Research Letters, 30(24), 2292. https://doi.org/10.1029/2003GL019002

Musial, G., Reynaud, J.-Y., Gingras, M. K., Féniès, H., Labourdette, R., \& Parize, O. (2012). Subsurface and outcrop characterization of large tidally influenced point bars of the Cretaceous McMurray Formation (Alberta, Canada). Sedimentary Geology, 279, 156-172. https://doi. org/10.1016/j.sedgeo.2011.04.020

Nanson, G. C. (1980). Point bar and floodplain formation of the meandering Beatton River, northeastern British Columbia, Canada. Sedimentology, 27(1), 3-29. https://doi.org/10.1111/j.1365-3091.1980.tb01155.x

Owen, A., Jupp, P. E., Nichols, G. J., Hartley, A. J., Weissmann, G. S., \& Sadykova, D. (2015). Statistical estimation of the position of an apex: Application to the geological record. Journal of Sedimentary Research, 85, 142-152. https://doi.org/10.2110/jsr.2015.16

Owen, A., Nichols, G. J., Hartley, A. J., Weissmann, G. S., \& Scuderi, L. A. (2015). Quantification of a distributive fluvial system: The Salt Wash DFS of the Morrison Formation, SW U.S.A. Journal of Sedimentary Research, 85, 544-561. https://doi.org/10.2110/jsr.2015.35

Pain, C., Clarke, J., \& Thomas, M. (2007). Inversion of relief on Mars. Icarus, 190(2), 478-491. https://doi.org/10.1016/j.icarus.2007.03.017

Pain, C. F., \& Oilier, C. D. (1995). Inversion of relief-A component of landscape evolution. Geomorphology, 12(2), 151-165. https://doi.org/ $10.1016 / 0169-555 \times(94) 00084-5$

Palucis, M. C., Dietrich, W. E., Hayes, A. G., Williams, R. M. E., Gupta, S., Mangold, N., et al. (2014). The origin and evolution of the Peace Vallis fan system that drains to the Curiosity landing area, Gale Crater, Mars. Journal of Geophysical Research: Planets, 119, 705-728. https://doi.org/10.1002/2013JE004583

Paola, C., \& Borgman, L. (1991). Reconstructing random topography from preserved stratification. Sedimentology, 38(4), 553-565. https:// doi.org/10.1111/j.1365-3091.1991.tb01008.x

Peterson, F. (1984). Fluvial sedimentation on a quivering craton: Influence of slight crustal movements on fluvial processes, Upper Jurassic Morrison Formation, western Colorado Plateau. Sedimentary Geology, 38(1-4), 21-49. https://doi.org/10.1016/0037-0738(84)90073-3

Reijenstein, H. M., Posamentier, H. W., \& Bhattacharya, J. P. (2011). Seismic geomorphology and high-resolution seismic stratigraphy of inner-shelf fluvial, estuarine, deltaic, and marine sequences, Gulf of Thailand. AAPG Bulletin, 95(11), 1959-1990. https://doi.org/ 10.1306/03151110134

Robinson, J. W., \& McCabe, P. J. (1997). Sandstone-body and shale-body dimensions in a braided fluvial system: Salt Wash Sandstone Member (Morrison Formation), Garfield County, Utah. AAPG Bulletin, 81 (1997)(8), 1267-1291. https://doi.org/10.1306/522B4DD91727-11D7-8645000102C1865D

Schumm, S. A. (1972). Fluvial paleo-channels. Special Publication-Society of Economic Paleontologists and Mineralogists.

Shiers, M. N., Mountney, N. P., Hodgson, D. M., \& Colombera, L. (2019). Controls on the depositional architecture of fluvial point-bar elements in a coastal-plain succession. In A. Ielpi, M. Ghinassi, R. H. Rainbird, D. Ventra (Eds.), Fluvial meanders and their sedimentary products in the rock record (Vol. 48, pp. 15-46). Hoboken, NJ: International Association of Sedimentologists. https://doi.org/10.1002/ 9781119424437

Slingerland, R., \& Smith, N. D. (2004). River avulsions and their deposits. Annual Review of Earth and Planetary Sciences, 32, 257-285. https://doi.org/10.1146/annurev.earth.32.101802.120201

Smith, N. D. (1972). Some sedimentological aspects of planar cross-stratification in a sandy braided river. Journal of Sedimentary Research, 42(3), 624-634. https://doi.org/10.1306/74D725E0-2B21-11D7-8648000102C1865D

Stokes, W. L. (1944). Morrison Formation and related deposits in and adjacent to the Colorado Plateau. Geological Society of America Bulletin, 55(8), 951-992. https://doi.org/10.1130/GSAB-55-951

Stokes, W. L. (1961). Fluvial and eolian sandstone bodies in Colorado Plateau. In SP 22: Geometry of sandstone bodies (Vol. A055, pp. 151-178). Tulsa, OK: American Association of Petroleum Geologists. Retrieved from http://archives.datapages.com/data/specpubs/ sandsto1/data/a055/a055/0001/0150/0151.htm

Trampush, S. M., Huzurbazar, S., \& McElroy, B. J. (2014). Empirical assessment of theory for bankfull characteristics of alluvial channels. Water Resources Research, 50, 9211-9220. https://doi.org/10.1002/2014WR015597

Trujillo, K. C., \& Kowallis, B. J. (2015). Recalibrated legacy ${ }^{40} \mathrm{Ar} /{ }^{39} \mathrm{Ar}$ ages for the Upper Jurassic Morrison Formation, Western Interior, USA. Geology of the Intermountain West, 2, 1-8. https://doi.org/10.31711/giw.v2.pp1-8

Turner, C. E., \& Peterson, F. (2004). Reconstruction of the Upper Jurassic Morrison Formation extinct ecosystem-A synthesis. Sedimentary Geology, 167(3-4), 309-355. https://doi.org/10.1016/j.sedgeo.2004.01.009

Tyler, N., \& Ethridge, F. G. (1983). Fluvial architecture of Jurassic uranium-bearing sandstones, Colorado Plateau, Western United States. In J. D. Collinson, \& J. Lewin (Eds.), Modern and ancient fluvial systems (pp. 533-547). Oxford, UK: The International Association of Sedimentologists. https://doi.org/10.1002/9781444303773.ch42

van de Lageweg, W. I., van Dijk, W. M., Baar, A. W., Rutten, J., \& Kleinhans, M. G. (2014). Bank pull or bar push: What drives scroll-bar formation in meandering rivers? Geology, 42, 319-322. https://doi.org/10.1130/g35192.1

Van den Berg, J. H. (1995). Prediction of alluvial channel pattern of perennial rivers. Geomorphology, 12(4), 259-279. https://doi.org/ 10.1016/0169-555X(95)00014-V

Ward, D. J., Berlin, M. M., \& Anderson, R. S. (2011). Sediment dynamics below retreating cliffs. Earth Surface Processes and Landforms, 36(8), 1023-1043. https://doi.org/10.1002/esp.2129

Williams, G. P. (1986). River meanders and channel size. Journal of Hydrology, 88(1-2), 147-164. https://doi.org/10.1016/00221694(86)90202-7

Williams, G. P. (1988). Paleofluvial estimates from dimensions of former channels and meanders. In V. R. Baker, R. C. Kochel, P. C. Patton (Eds.), Flood Geomorphology (pp. 321-334). New York: John Wiley \& Sons.

Williams, R. M. E., Chidsey, T. C., Jr., \& Eby, D. E. (2007). Exhumed paleo-channels in central Utah-Analogs for raised curvilinear features on Mars (pp. 221-235). Central Utah: Diverse Geology of a Dynamic Landscape.

Williams, R. M. E., Irwin, R. P., Burr, D. M., Harrison, T., \& McClelland, P. (2013). Variability in Martian sinuous ridge form: Case study of Aeolis Serpens in the Aeolis Dorsa, Mars, and insight from the Mirackina paleoriver, South Australia. Icarus, 225, 308-324. https://doi. org/10.1016/j.icarus.2013.03.016 
Williams, R. M. E., Irwin, R. P., \& Zimbelman, J. R. (2009). Evaluation of paleohydrologic models for terrestrial inverted channels: Implications for application to Martian sinuous ridges. Geomorphology, 107(3-4), 300-315. https://doi.org/10.1016/j. geomorph.2008.12.015

Williams, R. M. E., Irwin, R. P., Zimbelman, J. R., Chidsey, T. C., \& Eby, D. E. (2011). Field guide to exhumed paleo-channels near Green River, Utah: Terrestrial analogs for sinuous ridges on Mars. Geological Society of America Special Papers, 483, 483-505.

Witkind, I. J. (2004). Geologic map of the Huntington $30^{\prime} \times 60^{\prime}$ quadrangle, carbon, emery, grand, and Uintah counties, Utah (OFR-440dm). UT: Utah Geological Society.

Yingling, V. L., \& Heller, P. (1992). Timing and record of foreland sedimentation during the initiation of the Sevier orogenic belt in central Utah. Basin Research, 4(3-4), 279-290. https://doi.org/10.1111/j.1365-2117.1992.tb00049.x

Zimbelman, J. R., \& Griffin, L. J. (2010). HiRISE images of yardangs and sinuous ridges in the lower member of the Medusae Fossae Formation, Mars. Icarus, 205(1), 198-210. https://doi.org/10.1016/j.icarus.2009.04.003 